\title{
Article
}

\section{Collaborative Workplace Design: A Knowledge-Based Approach to Promote Human-Robot Collaboration and Multi-Objective Layout Optimization}

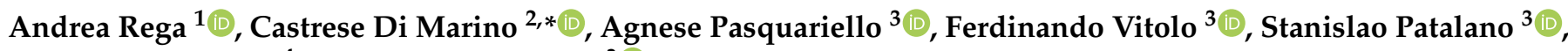 \\ Alessandro Zanella ${ }^{4}$ and Antonio Lanzotti ${ }^{3}$ (D) \\ 1 Department of Neurosciences, Reproductive and Odontostomatological Sciences, University of Naples \\ Federico II, 80131 Naples, Italy; andrea.rega@unina.it \\ 2 Department of Management, Information and Production Engineering, University of Bergamo, \\ 24129 Bergamo, Italy \\ 3 Fraunhofer J-Lab IDEAS, Department of Industrial Engineering, University of Naples Federico II, \\ 80125 Naples, Italy; agnese.pasquariello@unina.it (A.P.); ferdinando.vitolo@unina.it (F.V.); \\ stanislao.patalano@unina.it (S.P.); antonio.lanzotti@unina.it (A.L.) \\ 4 Centro Ricerche FIAT SCpA, 10043 Orbassano, Italy; alessandro.zanella@crf.it \\ * Correspondence: castrese.dimarino@unibg.it
}

\section{check for} updates

Citation: Rega, A.; Di Marino, C.; Pasquariello, A.; Vitolo, F.; Patalano, S.; Zanella, A.; Lanzotti, A. Collaborative Workplace Design: A Knowledge-Based Approach to Promote Human-Robot Collaboration and Multi-Objective Layout Optimization. Appl. Sci. 2021, 11, 12147. https://doi.org/10.3390/ app112412147

Academic Editor: Jürgen Reichardt

Received: 10 November 2021 Accepted: 14 December 2021 Published: 20 December 2021

Publisher's Note: MDPI stays neutral with regard to jurisdictional claims in published maps and institutional affiliations.

Copyright: (c) 2021 by the authors. Licensee MDPI, Basel, Switzerland. This article is an open access article distributed under the terms and conditions of the Creative Commons Attribution (CC BY) license (https:/ / creativecommons.org/licenses/by/ $4.0 /)$.

\begin{abstract}
The innovation-driven Industry 5.0 leads us to consider humanity in a prominent position as the center of the manufacturing field even more than Industry 4.0. This pushes us towards the hybridization of manufacturing plants promoting a full collaboration between humans and robots. However, there are currently very few workplaces where effective Human-Robot Collaboration takes place. Layout designing plays a key role in assuring safe and efficient Human-Robot Collaboration. The layout design, especially in the context of collaborative robotics, is a complex problem to face, since it is related to safety, ergonomics, and productivity aspects. In the current work, a Knowledge-Based Approach (KBA) is adopted to face the complexity of the layout design problem. The framework resulting from the KBA allows for developing a modeling paradigm that enables us to define a streamlined approach for the layout design. The proposed approach allows for placing resource within the workplace according to a defined optimization criterion, and also ensures compliance with various standards. This approach is applied to an industrial case study in order to prove its feasibility. A what-if analysis is performed by applying the proposed approach. Changing three control factors (i.e., minimum distance, robot speed, logistic space configuration) on three levels, in a Design of Experiments, 27 layout configurations of the same workplace are generated. Consequently, the inputs that most affect the layout design are identified by means of an Analysis of Variance (ANOVA). The results show that only one layout is eligible to be the best configuration, and only two out of three control factors are very significant for the designing of the HRC workplace layout. Hence, the proposed approach enables the designing of standard compliant and optimized HRC workplace layouts. Therefore, several alternatives of the layout for the same workplace can be easily generated and investigated in a systematic manner.
\end{abstract}

Keywords: Human-Robot Collaboration (HRC); Knowledge-Based Approach (KBA); digital layout optimization; what-if analysis

\section{Introduction}

Currently the innovative paradigm of "Industry 5.0" complements the existing "Industry $4.0^{\prime \prime}$ approach by counting on a human-centric industry. The hybridization of manufacturing plants with the collaboration between humans and robots was one of the main pillars of the "Industry 4.0 " framework and it becomes stronger within the "Industry 5.0" framework [1,2]. Furthermore, robotics is assuming an increasingly central role in manufacturing field due to innovation in automation and because of market pressure. The 
market and the companies in robotics acknowledge that collaborative robotics is the future of manufacturing and will willingly adopt the innovations created thus far by industry 4.0 and industry 5.0. Collaborative robotics offers the opportunity for replacing humans in all the tasks and operations that are considered to be alienating, thus creating a new role inside the collaborative workplace.

Even though a high level of automation allows for reducing the cost production [3], it reduces production flexibility, which is the main characteristic of a human-based workplace. Therefore, in the production context of mass customization, humans take on key role in the flexible manufacturing field. The new paradigm of "human centred design" and "anthropocentric design" [4,5] is approaching the plant and workplace design by enabling a synergistic cooperation of human skills and new industrial equipment. Therefore, despite the significant strength of automation, there are still several applications where human presence is essential. In such a context, Human-Robot Collaboration (HRC) is elevated to an enabling solution for mass customization that needs a high degree of flexibility [6]. Moreover, it is essential whenever either the processes are hard to automate or are affected by uncomfortable operations. However, effective collaborative workplaces are currently rare [7]. Most applications involve fenced cobots used as traditional industrial robots, or workplaces where the humans and the cobots coexist and perform different tasks on different workpieces without sharing tasks and/or space. A maze of standards, rules and guidelines [8], and the lack of a systematic approach to HRC workplace design are the main obstacles to a proper and efficient collaboration. Too often there is a conflict between unnecessary safety measures and productive needs. For these reasons, industry is still not confident and system integrators are hesitant to venture into HRC [9].

The layout design and optimization is a crucial aspect in the implementation of collaborative workplaces. An efficient layout must guarantee minimum movements, minimum travel time from one point to another, maximum utilization of resources, and the safety of human beings. The placement of the resources in the workplace area has a significant impact upon safety, lead times, work in process, productivity, and manufacturing cost. However, the layout problem is known to be complex and, despite its importance, the technical standards and most of the available design tools offer limited support for the layout configuration of HRC workplaces. Moreover, the solution of this problem becomes increasingly complex in the context of Human-Robot Collaboration, where the need to assure flexibility and high throughput must be combined with great attention to safety assessment.

Thus, the current paper proposes a Knowledge-Based Approach (KBA) to address the mess and uncertain characteristics of such complex scenarios by providing relationships, interactions, good practices, and rules to consider during the design phase. The collection, study, organization, and exploitation of the knowledge around HRC allowed for creating a strong basis framework. This rigorously identifies all the elements of the collaborative workplace and defines relationships among them. By means of this framework, the designer can outline the changes and their influence on all identified elements. Consequently, all this is used to develop a modeling paradigm that clusters the identified elements and the critical features that affect the workplace layout design. Via KBA and the paradigm, it is possible to understand and visualize how all the elements interact each other and which output a certain configuration that can be produced. Based on these considerations, we propose a layout design approach composed of four main steps for optimal positioning of the resources. The adopted optimization criterion consists of minimizing the occupied floor space. Keeping areas close together means reducing the distance that a human has to cover, thus also improving the cycle time. Furthermore, the optimization takes into account the constraints established by the regulatory framework that aim to achieve safe coexistence between humans and cobots. Finally, a what-if analysis and a ANOVA analysis are performed by the generation and evaluation of a set of scenarios related to an industrial use case. 


\section{Outline of the Paper}

The structure of the present manuscript runs from the acquisition of the knowledge in the Human-Robot Collaboration domain up to the definition of a systematic approach for HRC layout design. More specifically, the following main steps can be identified:

1. Knowledge Acquisition takes care of the exploration of the whole HRC domain. Information coming from academia, regulatory frameworks, and industry are selected and studied to identify who has influence on the collaborative workplace implementation.

2. Knowledge Management deals with the organizing of the collected knowledge in a structured and hierarchical form. The dense network of emerged information is managed using the graph theory.

3. Knowledge Representation allows us to identify what to focus on during the layout designing process. These can be summarized in the macro phase named KBA, which led to the following steps:

4. Definition of the modeling paradigm containing the main elements that affect the design of the HRC workplace layout. Their features, the constraints to which they are subjected, and the design parameters are collected and classified according to their influence on the layout designing.

5. Proposal of a structured approach, based on the paradigm, which addresses the problem of the HRC workplace layout designing according to an optimization criterion bound to compliance with the reference standards.

6. Application of the proposed approach in the designing of the layout of a collaborative workplace for quality inspection of welded parts in the automotive industry.

Finally, a what-if analysis is presented and a set of 27 configurations of the workplace layout is generated through the combination of three different parameters, i.e, minimum distance among the resources, relative position of the logistic spaces and robot speed, changing on three different levels. By means of the Simple Multi-Attribute Rating Technique (SMART) and the ANOVA analysis is proved that one layout configuration is eligible as the best, and only two control factors on three are very significant for the designing of the HRC workplace layout.

The aforementioned steps are detailed below, following an overview of the state of art.

\section{State of Art}

This paper addresses the design and optimization of a collaborative workplace layout. The facility layout problem is a well-known and widely addressed topic in recent decades [10-12]. However, in the context of collaborative robotics, it becomes a very complex problem to deal with, due to the several strongly coupled issues: task allocation problem, ergonomics aspects, interaction between the human beings and the machines, safety and standards compliance, and management problems that need to be considered in the layout designing. The most recent works addressing the topics intrinsically linked to the design and optimization of the HRC workplace layout are reported below.

Scimmi et al. [13], shows that when designing a collaborative application, particular attention must be paid to both the layout and the control strategy of the cobot. It proposes a collision avoidance algorithm based on repulsive velocities within a layout prototype for assembly operations. Assigning human being and cobot roles, the definition of the way they share tasks, influences the design choices regarding workplace layouts. Several approaches aimed at optimally allocating tasks to human and cobot, to fully exploit the synergistic effect of their collaboration, are proposed in the literature [14-16]. An effective design of the layout can improve the working conditions of the human operator and, at the same time, making the production process more efficient $[17,18]$. However, when designing a HRC workplace layout, it is necessary to consider physical and mental wellness of the human since the coexistence with a robot can make some tasks less tiring but, at the same time, it could produce stress for the operator [19]. Both physical [20] and cognitive ergonomics [21] need to be assessed. Elias Matsas et al. [22] investigated the acceptability of Human-Robot Collaboration in terms of mental safety issues, i.e., human's awareness and 
vigilance of the moving robot. They present a highly immersive Virtual Reality Training System (VRTS) named "beware of the robot" that simulates in real-time the cooperation between industrial robotic manipulators and humans executing simple manufacturing tasks.

Considering the interaction between human and robot, on the one hand the reference standards [23-25] suggest safety-based interaction between humans and robots, on the other hand several researchers propose different degrees of interaction that are no longer based only on the safety functions but considering the way they interact and carry out the tasks [5,26-29]. Ali Ahmad Mailk and Arne Bilberg [30] describe the interaction between humans and robots by means of an architecture based on a three-dimensional reference scale: team composition, level of engagement, and safety are the three considered dimensions. In [31], the authors propose the Digital Twin (DT) approach to address the complexity of achieving the full potential of Human-Robot Collaboration in assembly application. Kousi et al. [32] proposed a DT based approach for designing and redesigning flexible assembly system. The advantage resulting from the use of the DT is the possibility to dynamically update or reconfigure the workplace layout in response to the occurrence of unexpected events.

Boschetti et al. [33] focus on aspects related to the process and on the evaluation of its performance. The paper presents a mathematical model useful to evaluate the feasibility of a multi-resource collaborative assembly system and for making the most appropriate choices in the design phases. In [34], the authors investigate the influence of the product characteristics on HRC workplace design by developing an algorithm that simulates the product assembly in order to estimate the makespan realizable for several scenarios.

In [35], Tsarouchi et al. pursue a goal very close to ours. They face the problem of HRC workplace design starting from the task planning. Alternative layouts and task allocations are obtained by means of a multi-criteria decision making framework. Then, the different alternatives are evaluated. The approach does not consider compliance with the reference standard in the decision making framework. Ore et al. [36] identified the lack of methods supporting efficient HRC workstation design. They propose a step-by-step method useful in the early phases of the workstation design in the context of the Human-Industrial Robot Collaboration (HIRC). The method is based on the Pahl and Beitz's engineering design framework. It is used to design an assembly cell in the automotive context. The work highlights that advanced virtual simulation software should be used to generate more accurate data into the decision process. Lietaert et al. [37] present a methodology to optimize the design of a collaborative workplace according to spatial and ergonomic criteria. The authors took into account a detailed ergonomic evaluation in the formalization of the optimization problem, but they do not consider the standard constraints. The proposed approach was evaluated in a sheet metal manufacturing case study. Mateus et al. [38] proposed a structured design method addressing fundamental aspects for the designing of collaborative workplaces. They focused in particular on safety, ergonomics, time, and performance. Although [35-38] look in the same direction as the current work, they do not place enough emphasis on the safety aspect. In [39], the authors focus their work on the safety for human operators. They propose an industrial robot performance with a depalletizing operation as case study. The robot acts in a speed and separation monitoring mode, and human operators move in the surrounding space. There are no physical fences and a separation distance between humans and the robot must be guaranteed according to the ISO TS 15066. Usually the separation distance is calculated considering the worst-case scenario. The paper proposes an alternative approach that is useful for reducing the area of the workplace layout dedicated to maintaining the separation distance.

This overview of the state of art shows that the proposed tools and solutions, as well as the standards, are not sufficient for the development of a proper and effective collaborative workplace. The actual implementation of collaborative workplaces is hindered by the lack of an overall view of the topic. An approach that considers all the issues related to collaborative robotics and especially their relationships is still missing. It is necessary an appropriate approach that can lead to an optimal exploitation of the proposed solutions 
or tools, by providing relationships, interactions, and rules to consider during the design phase. Gervasi et al. try to face the identified gap in the literature by providing an analysis on several aspects, ranging from robotics to human factors. In [40], they propose eight latent dimensions in an HRC context and develop a framework for assessment of HRC applications. The Knowledge-Based Approach presented in the next section pursues the same goal. The KBA allows us to decompose the HRC domain into a hierarchical structure that is composed of elements and sub-elements most often linked by close relationship of interdependence. Finally, on the basis of the developed framework, an approach to HRC workplace layout design, which takes into account the issues highlighted by the academic research as well as the needs of the industry, the safety regulatory precepts are developed.

The proposed design approach allows to reduce the "routine-like" and "non-value adding" design tasks that require very little creativity. In this way, designers could make better use of their creativity and intuitiveness without being hindered by repetitive design tasks.

\section{A Knowledge-Based Approach for the Investigation of Collaborative Workplaces}

Human-Robot Collaboration is a very complex topic to deal with, due to several related relevant factors, e.g., programming and control, safety, level of interaction, ergonomics, and productivity. In this scenario, the only experience is not sufficient to address the design of the collaborative workplace and its layout. A structured approach intended to face all the issues related to this topic is needed. Knowledge-Based Approaches are largely applied to many engineering fields [41,42] such as software architecture [43] or decision making support for the management and development of complex systems and structures [44,45]. Accordingly, a KBA is proposed to achieve a general solution by collecting, organizing, and smartly making available the main information about collaborative robotics. The proposed KBA is composed of the three phases represented in Figure 1: (i) Knowledge Acquisition, (ii) Knowledge Management, and (iii) Knowledge Representation.

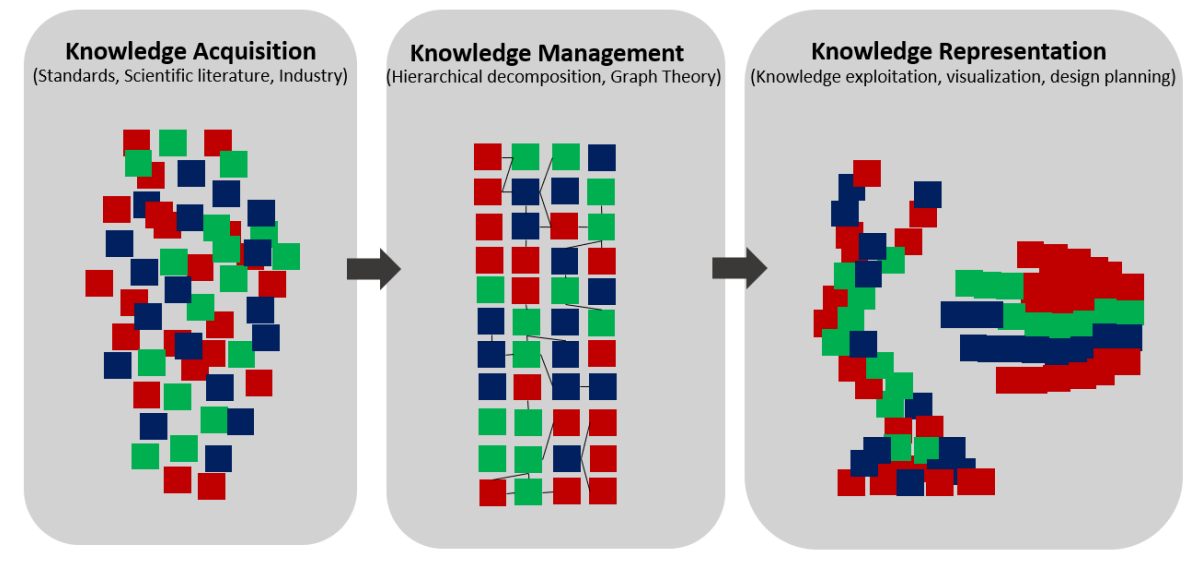

Figure 1. Depiction of the main phases of the Knowledge-Based Approach.

\subsection{Knowledge Acquisition}

The Knowledge Acquisition aims to acquire the necessary knowledge, establish a set of relations and rule, and generate usable datasets. The HRC field is analyzed from three points of view: (i) the scientific literature, (ii) the regulatory framework and (iii) the industrial context.

The overview provided in Section 2 allows for identifying the main areas of interest to deal with in the context of HRC workplace designing, according to the scientific literature: task allocation, safety, ergonomics, human-robot interaction, robot control, and so forth.

In the same manner, the study and the critical analysis of the regulatory framework leads to the identification of the main requirements for ensuring safety and risk reduction within an HRC workplace. However, a detailed discussion on standards is redundant 
considering that other works [46-48] already did it. It is sufficient to recall that the standards regarding robotics are organized into three types as follows:

- Type A standards: basic safety standards and requirements that apply to machinery.

- Type B standards: generic safety standards divided in two sub-categories.

- $\quad$ B1 standards concern specific safety aspects.

- B2 standards concern safeguard measures, interlocking devices, and optical or pressure sensors.

- Type C standards: safety requirements for specific machinery.

Among the latter type, it is worth mentioning the ISO/TS 15066:2016, which is the most recent standard in collaborative robotics and concerns the interaction between human and robot presenting four collaborative operations. Furthermore, it is a technical specification that describes in detail the allowed collaborative operations and specifies their requirements. It reinforces the indications given in ISO 10218-1/2 (Type C), that are the main standards concerning robots and robotic devices.

From the industrial point of view, analyzing [49,50], the following key points emerge:

- When grouping the applications of collaborative robots by sector, about three quarters of them belong to electrical engineering and automotive sectors. There are fewer applications in the plant engineering and mechanical fields.

- Focusing on the category of application, the majority of applications concern assembling or material handling.

- Applications where a worker really collaborates in strict contact with the cobot are not very common. In most of the cases, humans and robots coexist sharing the same workspace only occasionally. Furthermore, cobots are usually placed behind a physical fence and used in the same way as classic industrial robots.

Given the above, moving in this dense network of relationship and non-homogeneous information without a guide represents a grueling challenge. The acquired knowledge needs to be stored as rules, constraints, semantic representation, and facts to be easily manipulated. The following section shows how the large amounts of acquired information are managed and organized in a structured framework, thus enabling its exploitation in the context of the workplace layout design.

\subsection{Knowledge Management}

The Knowledge Management consists of the organization of the acquired knowledge into homogeneous "containers", and in the definition of the existing relationships among them. The knowledge associated with the collaborative workplace is divided in five main domains that collect all the homogeneous elements and respond to a specific need of the collaborative workplaces:

- Logistic domain: refers to all issues related to the division and management of the workspaces, the inclusive and exclusive working areas, the available space, and the management of the material flow strategy within the workplace layout.

- Technological domain: refers to all issues directly correlated with the involved resources, their features, number, and characteristics.

- Safety and ergonomics domain: refers to the human wellness, safety working conditions, and the performance of the control system, including the guards and protective devices.

- Process domain: refers to all issues related to the production, time, task sequencing, interaction, and communication between humans and robots.

- Economic domain: refers to costs and benefits about the collaborative workplace, as well as the performances evaluation.

Twenty-one elements belonging to these domains are presented below. They are parts or features of the collaborative workplace that face specific aspects of the problem and collect homogeneous information: 
1. Physical limits (PL): available space and any obstacles;

2. Workspaces (WS): division into the main workspaces that define the whole workplace layout;

3. Paths $(\mathrm{P})$ : accesses and exits of the workplace and related paths;

4. Feeding (F): means and strategies for material supply;

5. Workpiece (WP): main piece to be worked and its components;

6. Equipment (EQ): furniture and instruments;

7. Usable devices (UD): control devices under operator control;

8. Operator $(\mathrm{O})$ : operator characteristics;

9. Robot (R): robot characteristics;

10. Autonomous Guided Vehicle (AGV): AGV characteristics;

11. Ergonomics (ER): ergonomic constraints and limitations;

12. Environment (EN): environmental working conditions;

13. Minimum distances (MD): minimum distance set among both fixed and mobile resources;

14. Safeguarding perimeter (SP): physical or virtual workplace limit;

15. Safeguarding devices (SD): device not under operator control;

16. Type of work (TW): operation to be performed on the workpiece;

17. Task sequence (TS): elementary operations scheduled to be performed by humans and robots;

18. Human-Robot Collaboration (HRC): interaction between humans and robots;

19. Human machine interface (HMI): communication between human and robot;

20. Costs (C): economic constraints;

21. Benefits (B): key performance indicators (KPI).

Domains and elements represent the framework of the collaborative workplace (Table 1). Once the structured framework is defined, the subsequent need is to identify and represent the network of relationships among the elements. Therefore, the collaborative workplace is modeled as a graph $(\mathrm{G}=\mathrm{N}, \mathrm{E})$ [51] made of a set of nodes and edges [5] representing, respectively, the elements and their dependencies. The relations among the nodes are highlighted by means of a direct graph (digraph) or an adjacency matrix (Table 2) where the values 1 or 0 indicate whether the elements on the row have a direct connection with the elements on the columns, or not $[52,53]$.

Considering Table 2, the first seven columns (i.e., Workpiece,Type of work, Physical limits, Ergonomics, Environment, Minimum distances, and Costs) are intended as source nodes or external constraints. They are not influenced by the other nodes of the network. The central nodes are all configurations that depend on the designer's choices. The last nodes are intended as outputs of the design process, such as the workspaces and the paths that are the consequences of previous decisions. Thus, a flow going from the source nodes to the sink nodes is generated. The designer has an overall view of the topic at his disposal and can more consciously deal with the workplace layout planning, etc. 
Table 1. Decomposition matrix.

\begin{tabular}{|c|c|c|c|c|c|}
\hline Domains & Needs & Groups & Macro Aspects & Elements & Functionalities \\
\hline \multirow{4}{*}{ Logistic } & \multirow{4}{*}{ Management } & \multirow[b]{2}{*}{ Layout } & \multirow[b]{2}{*}{ Management of spaces } & Physical limits & Spatial constraints \\
\hline & & & & Workspaces & $\begin{array}{c}\text { Elementary and composed } \\
\text { workspaces }\end{array}$ \\
\hline & & \multirow{2}{*}{ Movement } & \multirow{2}{*}{ Management of flows } & Paths & Accessibility \\
\hline & & & & Feeding & Material flow strategies \\
\hline \multirow{6}{*}{ Technological } & \multirow{6}{*}{ Technical } & \multirow{3}{*}{ Passive resources } & \multirow{3}{*}{ Used to perform tasks } & Workpiece & Target to achieve \\
\hline & & & & Equipment & Supportive object \\
\hline & & & & Usable devices & Support for the operator \\
\hline & & \multirow{3}{*}{ Active resources } & \multirow{3}{*}{ Trained to perform tasks } & Operator & Operator features \\
\hline & & & & Robot & Robot features \\
\hline & & & & AGV & AGV features \\
\hline \multirow{5}{*}{ Safety and Ergonomics } & \multirow{5}{*}{ Safety and wellness } & \multirow{2}{*}{ Human } & \multirow{2}{*}{ Human wellness } & Ergonomics & Operators constraints \\
\hline & & & & Environment & Working conditions \\
\hline & & \multirow{3}{*}{ Safety } & \multirow{3}{*}{ Human safety } & Minimum distances & Distance among the resources \\
\hline & & & & Safeguarding perimeter & Workplace border \\
\hline & & & & Safeguarding devices & Safety devices \\
\hline \multirow{4}{*}{ Process } & \multirow{4}{*}{ Working } & \multirow{2}{*}{ Operations } & \multirow{2}{*}{ The aim of the workplace } & Type of work & Operation \\
\hline & & & & Task sequence & Task sequence and allocation \\
\hline & & \multirow[b]{2}{*}{ Interaction } & \multirow[b]{2}{*}{ Human-robot interaction } & HRC & Level of interaction \\
\hline & & & & HMI & $\begin{array}{l}\text { Human-machines } \\
\text { communication }\end{array}$ \\
\hline \multirow[b]{2}{*}{ Economic } & \multirow[b]{2}{*}{ Economic } & \multirow[b]{2}{*}{ Value } & \multirow[b]{2}{*}{ Benefits vs. costs } & Costs & Economic constraints \\
\hline & & & & Benefits & $\begin{array}{l}\text { Key Performance Indicators } \\
\text { (KPI) }\end{array}$ \\
\hline
\end{tabular}

Table 2. Adjacency matrix.

\begin{tabular}{cccccccccccccccccccccc}
\hline & WP & TW & PL & ER & EN & MD & C & O & R & AGV & EQ & UD & TS & HRC & HMI & F & WS & P & SP & SD & B \\
\hline WP & 0 & 0 & 0 & 0 & 0 & 0 & 0 & 1 & 1 & 1 & 1 & 1 & 1 & 0 & 0 & 1 & 0 & 1 & 0 & 0 & 0 \\
\hline TW & 0 & 0 & 0 & 0 & 0 & 0 & 0 & 1 & 1 & 1 & 1 & 1 & 1 & 0 & 0 & 0 & 1 & 0 & 0 & 0 & 0 \\
\hline PL & 0 & 0 & 0 & 0 & 0 & 0 & 0 & 0 & 0 & 0 & 0 & 0 & 0 & 0 & 0 & 0 & 1 & 0 & 1 & 0 & 1 \\
\hline ER & 0 & 0 & 0 & 0 & 0 & 0 & 0 & 1 & 0 & 0 & 0 & 1 & 0 & 0 & 0 & 0 & 0 & 0 & 0 & 0 & 0 \\
\hline EN & 0 & 0 & 0 & 0 & 0 & 0 & 0 & 1 & 0 & 0 & 0 & 0 & 0 & 0 & 0 & 0 & 0 & 0 & 0 & 0 & 0 \\
\hline MD & 0 & 0 & 0 & 0 & 0 & 0 & 0 & 0 & 0 & 0 & 0 & 0 & 0 & 0 & 0 & 0 & 1 & 0 & 0 & 0 & 0 \\
\hline C & 0 & 0 & 0 & 0 & 0 & 0 & 0 & 1 & 1 & 1 & 1 & 1 & 0 & 0 & 0 & 0 & 0 & 0 & 0 & 1 & 1 \\
\hline O & 0 & 0 & 0 & 0 & 0 & 0 & 0 & 0 & 0 & 0 & 1 & 1 & 1 & 1 & 1 & 1 & 1 & 0 & 0 & 1 & 1 \\
\hline R & 0 & 0 & 0 & 0 & 0 & 0 & 0 & 0 & 0 & 0 & 1 & 1 & 1 & 1 & 1 & 0 & 1 & 0 & 0 & 1 & 1 \\
\hline AGV & 0 & 0 & 0 & 0 & 0 & 0 & 0 & 0 & 0 & 0 & 0 & 0 & 1 & 0 & 0 & 1 & 0 & 1 & 0 & 1 & 1 \\
\hline EQ & 0 & 0 & 0 & 0 & 0 & 0 & 0 & 0 & 0 & 0 & 0 & 0 & 0 & 0 & 0 & 0 & 1 & 0 & 0 & 0 & 1 \\
\hline UD & 0 & 0 & 0 & 0 & 0 & 0 & 0 & 0 & 0 & 0 & 0 & 0 & 0 & 0 & 0 & 0 & 0 & 0 & 0 & 0 & 1 \\
\hline TS & 0 & 0 & 0 & 0 & 0 & 0 & 0 & 0 & 0 & 0 & 0 & 0 & 0 & 0 & 0 & 0 & 1 & 0 & 0 & 0 & 1 \\
\hline HRC & 0 & 0 & 0 & 0 & 0 & 0 & 0 & 0 & 0 & 0 & 0 & 0 & 0 & 0 & 0 & 0 & 1 & 0 & 0 & 1 & 1 \\
\hline HMI & 0 & 0 & 0 & 0 & 0 & 0 & 0 & 0 & 0 & 0 & 0 & 1 & 0 & 0 & 0 & 0 & 0 & 0 & 0 & 0 & 1 \\
\hline F & 0 & 0 & 0 & 0 & 0 & 0 & 0 & 0 & 0 & 0 & 0 & 0 & 0 & 0 & 0 & 0 & 1 & 1 & 0 & 0 & 1 \\
\hline WS & 0 & 0 & 0 & 0 & 0 & 0 & 0 & 0 & 0 & 0 & 0 & 0 & 0 & 0 & 0 & 0 & 0 & 1 & 1 & 0 & 1 \\
\hline P & 0 & 0 & 0 & 0 & 0 & 0 & 0 & 0 & 0 & 0 & 0 & 0 & 0 & 0 & 0 & 0 & 0 & 0 & 1 & 1 & 1 \\
\hline SP & 0 & 0 & 0 & 0 & 0 & 0 & 0 & 0 & 0 & 0 & 0 & 0 & 0 & 0 & 0 & 0 & 0 & 0 & 0 & 0 & 0 \\
\hline SD & 0 & 0 & 0 & 0 & 0 & 0 & 0 & 0 & 0 & 0 & 0 & 0 & 0 & 0 & 0 & 0 & 0 & 0 & 0 & 0 & 0 \\
\hline B & 0 & 0 & 0 & 0 & 0 & 0 & 0 & 0 & 0 & 0 & 0 & 0 & 0 & 0 & 0 & 0 & 0 & 0 & 0 & 0 & 0 \\
\hline
\end{tabular}




\subsection{Knowledge Representation}

The Knowledge Representation works to make the collected information understandable and usable by the designers, in order to better implement actions and corrections. The adjacency matrix allows for representing the structured information in a smart and intuitive form (see Figure 2).

In Figure 2a, the relations among all the elements of a collaborative workplace are depicted as digraph. All the connections start from the "source nodes" that are considered external inputs or constraints for the designer. The successive nodes need the information from the previous ones to be set.



Figure 2. Representation of the relationship among the elements of a collaborative workplace: (a) complete network; (b) input of node "workspaces" and their relationship.

Figure $2 b$ focuses on a specific node and presents all the inputs of the node "workspaces". The node "workspaces" is a more detailed breakdown of the workplace layout. A useful focus on this node is to identify which aspects are involved in the designing of the collaborative workplace layout. Figure $2 \mathrm{~b}$ shows a dense network of relationships among several nodes, which is not simple to take into account during the layout design. Moreover, it emerges that Physical limits, Minimum distances, Type of work, Task sequencing, HRC, Robot, Operator, Equipment, and Feeding are the main aspects to consider during the layout designing process of the collaborative workplace. These aspects are collected in the modeling paradigm presented in Section 4.1 to formalize their role in layout designing.

\section{The Layout Designing of the Collaborative Workplace Supported by a Modeling Paradigm}

In the context of Human-Robot Collaboration, the workplace layout design is a strenuous challenge as well as a central theme for the implementation of truly collaborative workplaces. An efficient HRC layout must guarantee minimum movements, minimum travel time from one point to another, maximum utilization of resources, and the safety of human beings. Several parameters, constraints, and issues must be taken into account to achieve efficient collaboration between human beings and robots. The KBA has provided a strong framework that shows useful results to identify these critical elements affecting the layout planning. Thus, a modeling paradigm is defined by exploiting the acquired and managed knowledge, and then, a systematic approach to the HRC layout design is developed according to the definitions and the concepts provided by the proposed paradigm.

\subsection{Modeling Paradigm}

The paradigm stems from the need to find a general model of the collaborative workplace. Standard archetypes are proposed to provide design criteria and constraints, making up for the lack of a univocal reference scheme. By means of problem decomposition 
on a side, and knowledge management on the other, it is possible to focus on the main elements that affect the design of HRC workplaces. The modeling paradigm contains rigorous definitions of these elements, analyzes their relationships, and clarifies how they affect the layout design. The guiding principle of this process is to look the workplace layout as a set of entities and identify the main models describing how they must be linked to their actual counterparts.

The following subsections present the elements composing the paradigm, the relationships among them, and the influence they exert on the HRC layout designing.

\subsubsection{Elements of Modeling Paradigm}

The collaborative workplace is modeled by defining (i) the physical entities that are part of it; (ii) the performed operations, on the one hand in terms of elementary tasks, and on the other, in terms of the type of robotic application; and (iii) the workspaces.

More specifically, the collaborative workplace is described in terms of its tangible components [54]. It consists of resources-a stock or supply of materials, staff, and other assets-that can be drawn on in order to carry out tasks on certain workpieces. The resources may be active or passive resources [35]. Active resources are defined as resources that are trained to perform a certain task. Robot systems and humans are active resources. On another hand, the passive resources such as fixtures, static structures, tables, logistic resources, and even machine tools, are used to perform a certain task. The workpiece is the object of the performed tasks. As already established by J. A. Marvel et al. [54], it can be composed of the principal component and any sub-components.

Then, the workplace is analyzed from a process-related perspective. The operation carried out in the workplace is described in terms of elementary tasks. After, the tasks are classified by type and by level of interaction between human beings and robots.

Three main task types are defined:

- Process task is a valued-added task; it can be performed by humans and/or robots, using either elementary tools or even machine tools.

- Transport task is a material handling task; it can be performed by human, cobot, mobile manipulators, simple AGVs, as well as by means of passive resources such as conveyors.

- Control task does not contribute materially to the actual processing; it has to be entrusted to human being since it concerns cobot control tasks. It could be performed by means of a human machine interface (HMI) such as pendant controller, smartwatch, tablet, or computer.

Tasks are further characterized by level of interaction between humans and robots. Based on the classifications already given in [27], this work proposes four level of interaction:

- Independent tasks: humans and robots perform different tasks on different workpieces.

- Sequential tasks: humans and robots perform different tasks on the same workpiece placed in the same position. They share the same workspace but at different times (the robot is inactive when a human enters the collaborative space).

- Parallel tasks: humans and robots perform separate tasks for the same goal at the same time. There is no physical contact between the human operator and the robot system. This level includes tasks which are performed inline.

- Collaborative tasks: humans and robots work cooperatively in order to complete the processing of a single workpiece. Contact is allowed (but not strictly necessary) since the robot and human can work "hand-in-hand".

Furthermore, the collaborative workplace is characterized according to the use made of the cobot(s) within it. The most common applications for which cobots installed by key vendors are employed, are showed in Figure 3. These applications are grouped into four main macro-categories according to their similarities, as follows: (i) Material handling when cobots are involved in the transport of material (e.g., pick and place, machine tending, packaging, palletizing, and parts orientations); (ii) Assembly/Disassembly when cobots 
perform screwdriving, nut fastening, etc.; (iii) Precision Machining when cobots perform soldering, gluing, milling, cutting, etc.; (iv) Inspection when cobots perform quality testing, non-destructive testing, and so on. Obviously, a workplace could be composed of multiple cobots used for different categories of application.

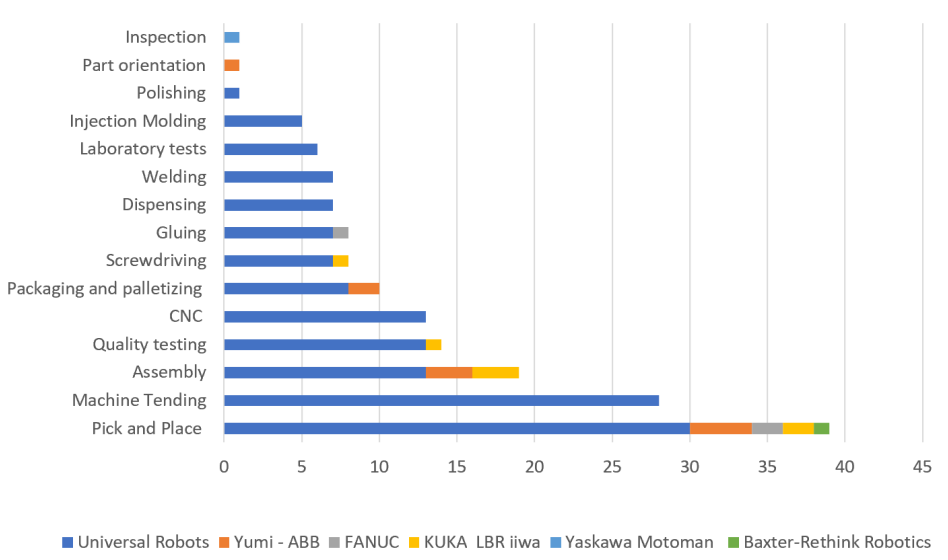

Figure 3. Most common applications for cobots installed by the key vendors.

Finally, the collaborative workplace is seen as the combination of several main workspaces: (i) the elementary workspaces dedicated to human operators and cobot, (ii) the composed workspaces identified through the combination of the elementary workspaces [5], and (iii) the logistic spaces.

Elementary workspaces. The collaborative workplace includes two elementary workspaces dedicated, respectively, to humans and cobots.

Human Space (HS) is the space where the operator can perform their tasks; it is the result of the envelope of N Unitary Human Spaces (UHSs), each dedicated to a specific task. The UHS is a circular area around the operator with a diameter equal to the arm span (AS). The AS is defined as the measurement of the length from one end of a person's arms to the other, when raised parallel to the ground at shoulder height and at a $90^{\circ}$ angle. The space occupied by the operator is described by means of the body ellipse whose minor and major axes, respectively, represent depth and width of the human body. To be thorough, it is necessary to consider the increase in space due to the operator's clothing [55]. Zones of convenient reach are the areas that can be reached comfortably through movements that do not involve effort. These areas are included inside the UHSs and contain the Human Task Area (HTA). The HTA is a circular area dedicated to carry out the tasks that compose the whole operation. The center of this circular area is called Human Task Center (HTC). Figure 4 depicts the above-defined areas.

Robot Space (RS) is the space needed by the robot system (including attached tool and workpiece) to perform all its tasks. This space does not necessarily correspond to the maximum space that the robot can reach. It is usually defined through a safety-rated soft axis and space limiting, as described in ISO 2018-1:2011. Practically, the robot system motion is software-defined and the space limiting is used to identify a space of any geometric shape where robot motion is limited [23]. However, robot space may be seen as the composition of $\mathrm{N}$ elementary robot spaces one for each task. The center of each intended space is named a Robot Task Center (RTC).

Composed workspaces. Composed workspaces are obtained from the combination of the elementary workspaces: Collaborative Space (CS) is the intersection of the human and robot space. It is present only if one of the established tasks is carried out in collaborative modes. In this case, it is possible to define a Collaborative Task Center (CTC) as the center of the CS. 


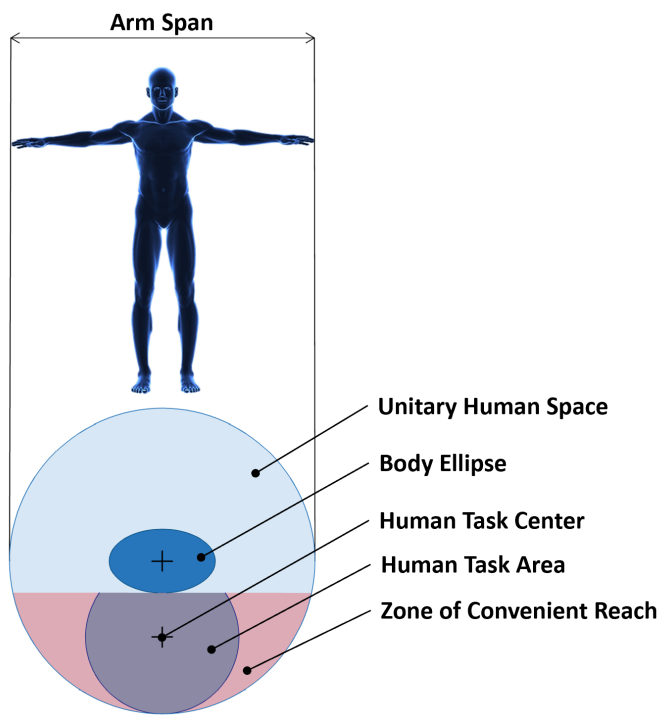

Figure 4. Human Space representation.

Operational space (OS) is the sum of the elementary spaces and represents the space needed to perform all the intended tasks. It includes the Collaborative Space.

Logistic spaces. The spaces through which the workplace interfaces with the parts coming from the outside and the materials directed toward the outside are defined as logistic spaces. The logistic spaces are classified as follows:

1. The infeed spaces receive from the outside the workpiece, supply materials as screws, nuts, bolts, single parts to be assembled, sub-assemblies to be completed, and groups to be processed.

2. The outfeed spaces receive the processed parts directed outwards. The outfeed spaces dedicated to correctly processed parts should be different from the outfeed spaces dedicated to parts which do not satisfy quality standards and must be reworked or discarded.

Shape and size of the logistic spaces are dependent on the geometric features of the logistic resources used to load/unload, for storage, and to handle the workpieces. The position of the logistic spaces depends on the specific case. A valid solution could be to place the logistic spaces on the workplace sides. The possible scenarios are the following (Figure 5):

1. Infeed and outfeed spaces are placed near consecutive sides;

2. Infeed and outfeed spaces are placed near opposite sides;

3. Infeed and outfeed spaces are placed near the same side.



a

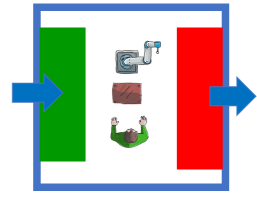

b



C

Figure 5. Possible position of Logistic Spaces: (a) infeed and outfeed spaces are on consecutive sides; (b) infeed and outfeed spaces are on opposite sides; (c) infeed and outfeed spaces are on the same side.

However, continuous flow manufacturing systems do not fall under the above classification. For example, in the automotive field, the assembly process usually involves the movement of the principal part on a central conveyor and the arrival of the sub-assemblies through suitable logistic resources. Therefore, on the one hand, the sub-assemblies arrive 
at the workplace side in the infeed spaces, on the other hand, the principal part crosses the workplace following a defined path, entering from one specific point and leaving from another.

Considering that both the robot and human can pick up parts from the logistic spaces to carry on the assigned tasks, it is clear that these spaces can be included entirely or be part of the elementary spaces.

Table 3 recapitulates synthetically the elements that are part of the proposed modeling paradigm.

Table 3. Elements of modeling paradigm.

\begin{tabular}{|c|c|c|}
\hline & odeling Paradigm Elemer & \\
\hline \multirow{3}{*}{ Workplace components } & Active resources & Human operator Cobot \\
\hline & Passive resources & Fixtures Machine tools \\
\hline & Workpieces & Main part Subcomponents \\
\hline \multirow{2}{*}{ Task attributes } & Task type & $\begin{array}{l}\text { Process task } \\
\text { Transport task } \\
\text { Control task }\end{array}$ \\
\hline & Level of interaction & $\begin{array}{l}\text { Independent } \\
\text { Sequential } \\
\text { Parallel } \\
\text { Collaborative }\end{array}$ \\
\hline \multirow{4}{*}{ Category of application } & Material handling & $\begin{array}{l}\text { e.g., pick and place, machine } \\
\text { tending, palletizing }\end{array}$ \\
\hline & Assembly & e.g., nut fastening, screwdriving \\
\hline & Precision machining & $\begin{array}{l}\text { e.g., welding, soldering, gluing, } \\
\text { milling }\end{array}$ \\
\hline & Inspection & e.g., quality testing \\
\hline \multirow{3}{*}{ Workspaces } & Elementary workspaces & $\begin{array}{l}\text { Human Space } \\
\text { Robot Space }\end{array}$ \\
\hline & Composed workspaces & $\begin{array}{l}\text { Collaborative Space } \\
\text { Operational Space }\end{array}$ \\
\hline & Logistic Space & $\begin{array}{l}\text { Infeed Space } \\
\text { Outfeed Space }\end{array}$ \\
\hline
\end{tabular}

4.1.2. The Relationship among the Elements of the Paradigm and the Layout Designing

Every element of the paradigm affects the layout designing in a specif way; their influences on the whole workplace and the relationships among them are described below.

Each of the categories of application identified in the previous paragraph corresponds to a basic configuration of the workplace layout. Therefore, each basic configuration is characterized by some main elements and feature that are always present for that specific category. All the cobots used for a specific application are characterized by the same main features. Moreover, each category of application may prefer a specific level of interaction. For example, Assembly applications mostly involve human being and cobot carrying out tasks in close contact. This means that tasks are mostly performed on a single item cooperatively and Human and Robot Spaces inevitably intersect. Instead, Inspection applications usually involve the non-simultaneous sharing of spaces between humans and cobots and requires the separation distance to be guaranteed.

The definition of the "type" and "level of interaction" for each task inherently provides information about the relative position between humans and cobots within the workplace. Combining the information about the task attributes with the main configuration related to the category of application, a rough workplace layout begins to take place. Knowing that the cobot performs an inspection, and the human supervises in a collaborative way after having performed other tasks, resources can be identified and arranged within the workplace layout in a certain way, e.g., aiming to minimize the human movements during the execution of tasks. 
The characteristics of the resources, as well as those of the workpieces, influence the definition of the entire layout. The number, the size, the reach of the robot, affect the definition of the workspaces. The position of the resources within the workplace depends on some of their characteristics.

Workspaces are mostly influenced by the other elements of the paradigm. Position, size, and shape of the workspaces depends on the characteristics of the tasks and workplace components. Moreover, the definition of workspace features affect not only the layout but also the whole process: they ease or hinder the process causing unreachability, distances that are too long to cover, etc.

In short, the paradigm can serve three kinds of purposes:

1. Describes the relevant aspects of the workplaces;

2. Simplifies the implementation of designing methods;

3. Identifies changes in the layout of the workplaces.

\subsection{Problem formalization}

It is possible to formalize the HRC workplace layout designing problem by expressing the elements of the paradigm in the following way:

1. Set of passive resources $P$ (previously defined in Section 4.1.1) located within the workplace floor with pose defined as $\left\{x_{p_{i}}, y_{p_{i}}, \theta_{p_{i}}\right\} \forall p_{i} \in P$; each passive resource can be characterized by a set of points of interest, e.g., geometrical center of gravity, vertices, and points reachable by active resources;

2. Set of active resources $A$, i.e., robots and human operators as stated in Section 4.1.1, each one characterized by a series of attributes and skills;

3. Set of elementary tasks that have to be performed by the active resources or by using passive resources (e.g., machine tools); each task is described by type and level of interaction as stated in Section 4.1.1;

4. Set of task centers (i.e., HTC, RTC, and CTC as defined in Section 4.1.1) within the workplace $W$ with pose expressed as $\left\{x_{w_{i}}, y_{w_{i}}\right\} \forall w_{i} \in W$;

5. Set of basic locations within the workplace that correspond to the position where workpieces enter/exit the workplace (see the Logistic Spaces definition in Section 4.1.1).

Therefore, considering the above definitions, the solution to the design of the layout of the collaborative workplace could be expressed in matrix form by the following entities:

1. A matrix $T_{t c}$ of task-task center assignments;

2. A matrix $L_{c p}$ of task center-passive resource assignments;

3. A matrix $F_{a p}$ of active resource-passive resource assignments.

This means that the proposed approach helps the designer in defining the optimized and standard compliant layout by identifying the task centers and defining their stances within the workplace according to an optimization criterion.

The optimization problem consists of finding a vector $w$ that minimizes a nonlinear objective function $f(w)$ subject to nonlinear constraints and bound constraints. It is known in the literature as a constrained nonlinear programming problem (NLP) [56]. The constraints are expressed by means of inequalities or equalities.

Therefore, it is possible to formulate the current problem as:

$$
\min _{w} f(w) \text { subject to }\left\{\begin{array}{l}
g(w) \leq 0 \\
g e q(w)=0 \\
l b \leq w \leq u b
\end{array}\right.
$$

with

$$
f(w)=a_{1} E(w)+a_{2} S(w)+a_{3} G(w) ;
$$

where $w$ is the vector containing the Cartesian coordinates of the identified task centers; $g(w)$ and $g e q(w)$ represent the constraints as equalities and inequalities; $l b$ and $u b$ stand for lower bounds and upper bounds. In Equation (2), E(w) takes into account the ergonomic 
aspect, $S(w)$ is the occupied floor space within the workplace and $G(w)$ is an additional indicator; $a_{1}, a_{2}$, and $a_{3}$ are weighting factors.

\subsection{Proposed Approach}

The main purpose of the current paper is to deal with the HRC workplace layout designing problem in a systematic and structured fashion, by means of the adoption of standardized reference models. The resulting approach is an iterative process, consisting of four main phases (Figure 6): (i) task analysis; (ii) task centers allocation; (iii) constrained optimization problem solving; (iv) rough layout definition. The process inputs are spatial constraints (i.e., available space, any obstacles, logistic spaces configuration) and the operational features (i.e., task sequence and assignment, material flow strategy). Thus, task allocation needs to be done at an earlier stage, in order to optimally plan the activities among the available resources. Downstream of the layout generation, a risk assessment could highlight the necessity of further risk-reduction measures, e.g., additional safety sensors, changes to the task assignment, resources, and environment. Therefore, the layout design is not a linear process since the iteration loops to previous phases are fundamental. The process is described in the following, where each phase is denoted at the beginning of the indention in italic.

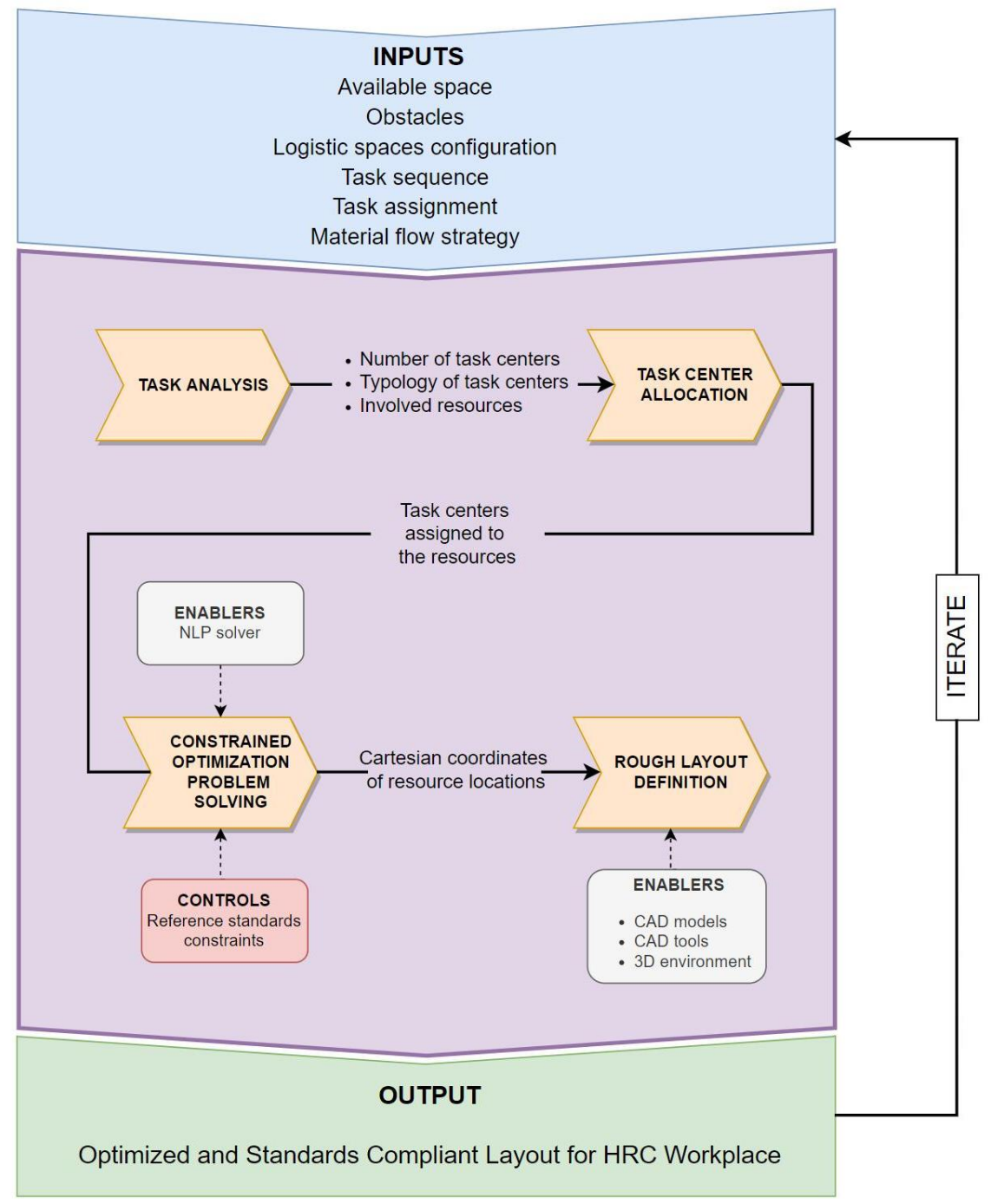

Figure 6. The proposed approach for the layout designing of the HRC workplace. 
Task analysis. Assuming that the scheduling and the allocation of tasks are defined in advance as process input, the present approach involves the task analysis as the first step of the whole designing process. The analysis of the task assignment aims to identify the entities previously described in the modeling paradigm (see Section 4.1): the process is described in terms of elementary tasks, each one characterized by "typology" and "level of interaction"; the complete set of resources and the corresponding tasks are identified; the reach, the payload, the size, and the maximum speed of the robot, as well as the percentile, the gender of the human being, and the dimensions of the passive resources are defined.

The final goal of this process is the definition of the matrix $T_{t c}$ containing the number and the type (i.e., HTC, RTC, or CTC) of the task centers associated with the corresponding tasks. Every task is characterized by type and level of interaction between human operator and robot. The combination of this information returns the desired output. In particular, "transport" task implicates two task centers, one as the starting point and one as the arrival point, whether it is a robot task or a human task. "Process" and "control" tasks implicate one task center each. The level of interaction between human and robot establishes whether the task centers are coincident or not: for "independent" task, since human and robot perform different tasks on different workpieces, HTC and RTC are different; if the interaction between human and robot is at "sequential" level, HTC and RTC coincide in the space but in different time (robot and human are active one at time); the "parallel" level of interaction entails simultaneous tasks, aimed at the same goal, in different task centers; "collaborative" level of interaction means robot and human working in close contact and therefore coincident task centers.

Task center allocation. This phase entails the association between task centers and passive resources allowing to define the matrix $L_{c p}$. The task center defined for a specific operation is made to coincide with a point of interest belonging to the relative passive resource. Hence, this point becomes the origin of a local reference frame anchored to the resource. The local frame is then positioned and oriented with respect to the global reference. The authors have assumed the point of interest as the geometric center of gravity of the resource. Hence, the position of the passive resource required to perform a specific task can be determined by defining the position of the task center related to that specific task.

Constrained optimization problem solving. In the previous subsection the goal function to be minimized was defined by Equation (2). That function is the sum of several terms related to specific features of the workplace. Currently, the present paper takes into account only the aspect related to the occupied floor space $S(w)$. The occupied floor space minimization criterion guarantees the best solution when it is necessary to reduce the dimension of the workplace and it also goes to meet the need to reduce the distances covered by the human operator in order to enhance the ergonomic conditions during the execution of his tasks. Ergonomic aspects will be considered in more detail in the future developments of this approach.

Therefore, considering the workplace floor space utilization [35] as:

$$
F S=\left(x_{\max }-x_{\min }\right)+\left(y_{\max }-y_{\min }\right),
$$

where $x$ and $y$ are the maximum and the minimum coordinates reached by any resource in the plane, the goal function is defined as the sum of the Euclidean distances between the pairs of task centers:

$$
f=\sum_{k=1}^{b} \sqrt{\left(x_{k, i}-x_{k, j}\right)^{2}+\left(y_{k, i}-y_{k, j}\right)^{2}} .
$$

The $x_{i}, y_{i}$, and $x_{j}, y_{j}$ in Equation (4) are the Cartesian coordinates of the $i$-th and $j$-th task centers, respectively; $b$ represents the number of simple combinations given by: 


$$
\left(\begin{array}{l}
n \\
2
\end{array}\right)=\frac{n !}{2 !(n-2) !},
$$

where $n$ is the number of tasks centers to be placed in the available space.

Minimizing the Euclidean distances between the task centers means that the resources are placed closer together, and consequently, the occupied floor space is also reduced.

Obviously, the problem is constrained to place the resources within the available space and to avoid overlap of them. Furthermore, the solution of the optimization problem is bound to compliance with the following provisions established by the reference standards:

- The minimum distance between moving objects, the robot system and building areas, structures, users, and other machines should be at least $500 \mathrm{~mm}[24,57]$.

- The minimum required separation distance between humans and robots established by the ISO/TS15066 [25] with regard to speed and separation monitoring is:

$$
S_{p}(t)=S_{r}+S_{r}+S_{s}+C+Z_{d}+Z r .
$$

The standard clarifies well how each term is determined.

- Safety distances are required to guarantee escape routes [58].

- The positioning and the orientation of the control device (e.g., the Human Machine Interface) should be such that the view on the robot is always unobstructed (as declared in the Annex A of ISO 10218-2 [24] and ISO 13850 [59]).

- Maximum load carrying distance should be defined depending on the carried cumulative mass [60].

Moreover, logistic space, which contains the logistic resources, can be bound to assume one of the three configuration described in Section 4.1.

In short, the mathematical modeling for the optimization problem is set up as the search for the minimum value of a nonlinear function of $n \times 2$ variables subject to nonlinear constraints. The constraints are expressed by means of equalities and inequalities. The $n \times 2$ variables correspond to the Cartesian coordinates $(x, y)$ of the plan projection of the $n$ task centers associated with the relative passive resources. The problem is solved by means of a Matlab nonlinear programming solver.

Rough layout definition. This phase outcome is the optimized and standard-compliant principal solution to the HRC layout designing problem. Once the optimization problem is solved, and the passive resources are placed, the working areas are determined by defining the matrix $F_{a p}$ that associates the active resources to the employed passive resources. The proposed approach identifies as the main workspaces the Human Space and the Robot Space, and using the definitions proposed in the paradigm, it is easy to mark them. Conceptually, the first attempt layout could look similar to the solution shown in Figure 7. As it can be seen from the figure, the task centers (i.e., HTC, RTC, and CTC) and the related passive resources, whose poses are determined by solving the NLP problem, the Human Space, the Robot Space, and the Logistic Space, where the workpieces enter and exit the workplace, are explicitly identified. 




Figure 7. Conceptual layout of the HRC workplace optimized by computing the placement of Human Task Centers (i.e., HTC1, HTC2, HTC3, and HTC C) and Robot Task Center (i.e., RTC1). The coincidence between HTC2 and RTC1 identifies the Collaborative Task Center (CTC) within the Collaborative Space.

\section{Case Study}

In this paragraph, the approach presented above is used for designing a HRC workplace layout for quality inspection of welding points on automotive components. Then, a what-if analysis is presented to evaluate how the layout is affected by changing some input parameters.

\subsection{Collaborative Workplace for Inspection of Welded Parts}

The proposed case study is a collaborative workplace that concerns the welding points quality check carried out by means of ultrasonic technology. It involves the adoption of a human operator and a cobot. The operator is concerned with taking and carrying the component whereas the cobot executes the inspection. The cobot is equipped with a specially designed ultrasonic end-effector. The workpiece to be inspected requires a precise adjustment on the dedicated stand. After the inspection, the operator picks up the component from the dedicated stand and deposits it on the outfeed stand. The main activities of the operator are: carrying the component, precise positioning it and monitoring as long as the cobot execute the inspection. The aim of this section is to generate an optimized layout by means of the proposed Knowledge-Based Approach. For this reason, the parameters of the quality inspection as well as the part to inspect, are not considered during the designing of the layout. The authors focus the attention on the category of application, i.e., Inspection, rather than the specificity of the case study.

The four steps of the proposed approach, i.e., (i) task analysis, (ii) task centers allocation, (iii) constrained optimization problem solving, and (iv) rough layout definition, are applied aiming at designing a standard compliant and optimized layout for this case study.

Task analysis. The task assignment (Figure 8 ) is analyzed as the main input of the entire process. The task analysis allows defining the elements formalized in Section 4.2:

1. The set of involved passive resources $P$;

2. The set of involved active resources $A$;

3. The set of elementary tasks composing the entire operation and their attributes (i.e., type and level of interaction);

4. The set of the task centers distinguished by type (i.e., HTC, RTC, and CTC) according to the procedures described in the previous chapter.

Table 4 indicates the details of the information obtained from the task analysis including the task centers list related to all tasks. Thus, the matrix $T_{t c}$ of task-task center assignments introduced in Section 4.2 can be deduced from Table 4 . 


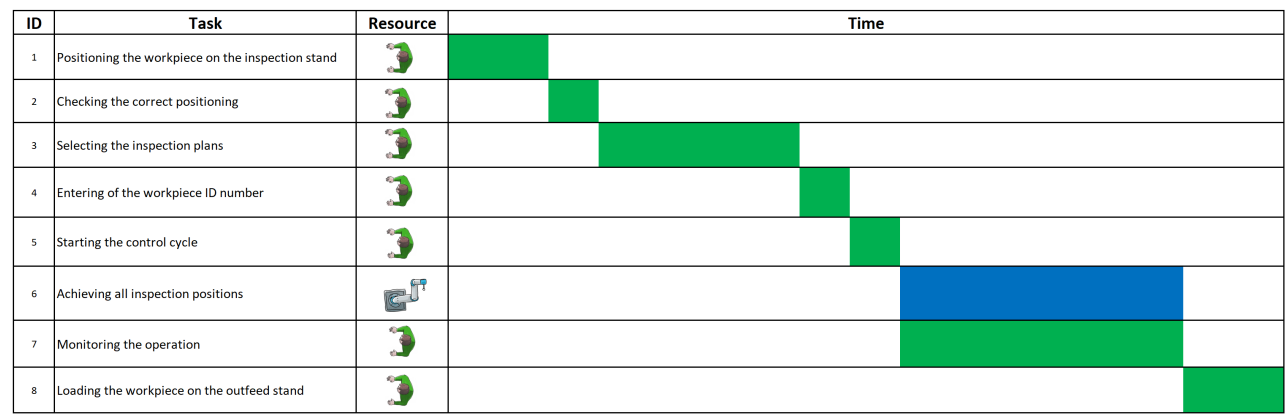

Figure 8. Task assignment related to the quality check of welding points performed in a collaborative manner.

Table 4. The information emerging from the task analysis.

\begin{tabular}{|c|c|c|c|c|c|}
\hline ID & Task & Task Type & Active Resource & Level of Interaction & Task Center \\
\hline 1 & $\begin{array}{l}\text { Positioning the workpiece on the } \\
\text { inspection stand }\end{array}$ & Transport & Human Operator & Sequential & HTC 1-HTC 2 \\
\hline 2 & Checking the correct positioning & Process & Human Operator & Sequential & HTC 2 \\
\hline 3 & Selecting the inspection plans & Control & Human Operator & Sequential & HTC C \\
\hline 4 & Entering workpiece ID number & Control & Human Operator & Sequential & HTC C \\
\hline 5 & Starting the control cycle & Control & Human Operator & Sequential & HTC C \\
\hline 6 & Achieving all inspection positions & Process & Cobot UR10 & Collaborative & RTC $1=$ HTC2 \\
\hline 7 & Monitoring the operation & Process & Human Operator & Collaborative & HTC 2 \\
\hline 8 & $\begin{array}{l}\text { Loading the workpiece on the } \\
\text { outfeed stand }\end{array}$ & Transport & Human Operator & Sequential & HTC 2-HTC 3 \\
\hline
\end{tabular}

The chosen collaborative robot is a UR10 cobot produced by Universal Robot, with performance level " $\mathrm{d}$ ", category 3 according to ISO 13849 [61]. It has six rotational joints, a payload of $10 \mathrm{~kg}$ and 1.3 meters of maximum reach. The cobot is equipped with an end-effector tool that enables the robot to accomplish the inspection activity. A dedicated Human Machine Interface (HMI) simplifies the cobot control and improves the HumanRobot Collaboration.

The set of required passive resources is the following:

1. Infeed stand;

2. Outfeed stand;

3. Inspection stand;

4. Robot pedestal;

5. Human Machine Interface.

According to the proposed approach, "transport" task needs two task centers: the first task, i.e., "loading workpiece in the control station", needs the Human Task Center 1 where the operator takes the workpiece, and the Human Task Center 2 where the operator places it. The following tasks are "process" or "control" tasks, performed sequentially on the same workpiece. Therefore, they are all executed at Human Task Center 2 and Human Task Center $C$. Task 6 is assigned to the cobot that has to achieve all the inspection positions. The cobot carries out the task under the human supervision, in a collaborative manner. This means that the Robot Task Center 1 coincides with the Human Task Center 2, identifying a Collaborative Task Center. Moreover, task 7, linked to Human Task Center 2, is the collaborative task performed by the human being. It does not involve physical contact between the resources, but it is carried on in the same workspace, on the same workpiece and at the same time. However, the minimum separation distance is guaranteed. Finally, tasks 3, 4, and 5 are "control" tasks. They do not contribute to the actual process but concern the cobot control. The related task center is different from those previously identified. It affects the position of the HMI within the available space. Task 8 , i.e., "loading workpiece in the storage station", is treated as task 1 since it involves the transport of the workpiece from Human Task Center 2 to Human Task Center 3. 
Task center allocation. Then, the passive resource, which is needed to carry out a specific task, is associated with the task center related to that task by setting the matrix $L_{c p}$ of task center-passive resource assignments (see Section 4.2). In particular, the infeed and outfeed stands are associated, respectively, to the Human Task Center 1 and 3, whereas the inspection stand is associated with Human Task Center 2 (that coincides with Robot Task Center 1). Finally, the Human-Machine Interface is associated with Human Task Center C. The robot pedestal supports the cobot.

Constrained optimization problem solving. This phase consists of defining the task centers position. As a result, the related passive resources are also placed. The available space is a rectangular area of 49 square meters. There are no pre-existing obstacles. The position of the logistic spaces (i.e., the set of basic locations within the workplace where the workpiece enters/exits as defined in Section 4.2) is defined considering the possible scenarios presented in Section 4.1.1. The solution of the constrained optimization (see Equations (1) and (2)), which minimizes the occupied floor space (see Equation (3)), is found by means of a Matlab solver.

Rough layout definition. The elementary workspaces are identified by defining the matrix $F_{a p}$ of active resource-passive resource assignments (see Section 4.2). The envelope of the four Unitary Human Spaces (UHSs), which are needed to carry out all the tasks assigned to a human, identifies the Human Space. The Robot Space is software-defined. The intersection between the elementary spaces identifies the Collaborative Space, while their union identifies the Operational Space. The logistic spaces intersect the Human Space. Infeed space and outfeed space are placed on the same side according to the presented possible scenarios (see Section 4.1.1). Figure 9 shows the layout obtained by applying the proposed approach. At the end of the design process, the workplace can be completed with additional fixtures and safety devices if these are really needed.

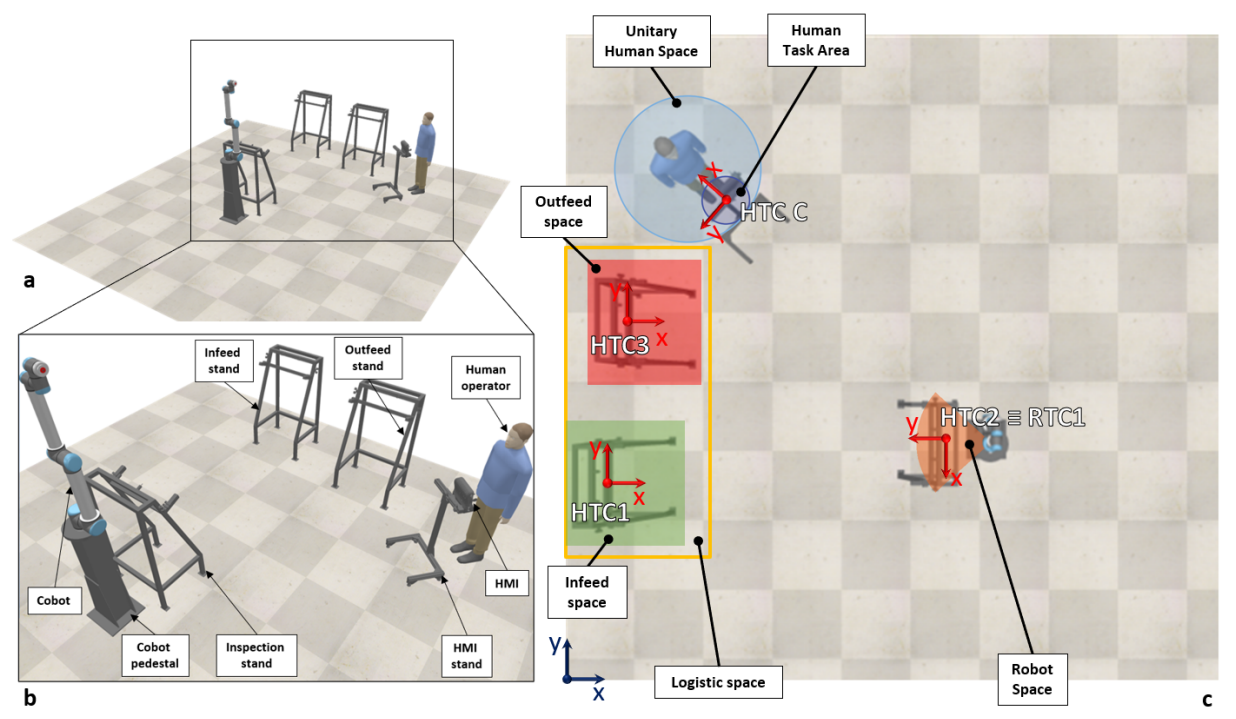

Figure 9. The HRC workplace layout obtained by means of the proposed approach: (a) the workplace showed in the 3D environment; (b) 3D enlargement showing the several resources that are part of the workplace; (c) 2D view highlighting the several task centers and the main workspaces.

\subsection{What-If Analysis}

In this section, a what if analysis that involves the generation and subsequent evaluation of several scenarios is presented. In the first stage, the proposed approach is used to generate several collaborative workplaces starting from different sets of inputs. In particular, three input parameters are fixed on three levels in order to create 27 different combinations. Consequently a critical assessment of them is carried out through some criteria in order to find out the best configuration and combination of parameters. Afterwards, the impact of the selected parameters on the performances of the system is evaluated. For this purpose, 
four Key Performance Indicators (KPIs) of the workplace are evaluated by means of specific functions. Then, an utility value given by the combination of that functions is obtained by means of the Simple Multi-Attribute Rating Technique (SMART) [62-64]. This technique is a synthetic value that combines several non-homogeneous quantities and provides an utility value through four steps:

- Assigning a weight to each function or performance by means of a comparison among them;

- Making the output value of each function dimensionless and on a normalized scale making the best of each function corresponded to the maximum in the normalized scale;

- Multiplying the dimensionless values and the weights;

- Summing the results obtained in the previous step.

The output value of this technique is a weighted combination of the other performances and the highest value identifies the best configuration among to the different combinations of parameters.

The input parameters of this analysis, selected as control factors, are:

1. Minimum distance: the minimum distance among the resources;

2. Robot speed: the speed adopted by the robot to carry out the inspection;

3. Logistic spaces: the relative position of the logistic spaces.

According to the ISO 13854 [57], the minimum distance among the resources must not be lower than $500 \mathrm{~mm}$. In the context of the spatial optimization, it represents the lower limit. On another hand, according to the designing and production purposes, it could be required this value higher to guarantee specific needs. Indeed, even tough the optimization algorithm points to the minimization of the distances, there is always a minimum value to be guaranteed, not only due to the safety, but also for the working exigences. Then, the robot speed influences several key aspects of the workplace such as the timing, the safety, the proximity of the human to the robot, and the collaborative time. Finally, the relative position of the logistic spaces, as explained in Section 4.1.1 can be set at the same side, consecutive sides or opposite sides in a single workplace, with an impact on the logistic optimization that depends on the manufacturing context.

The selected parameters belong to a specific domain of the collaborative workplace (Table 1). The minimum distance is a safety requirement, the robot speed is a technical parameter related to the active resource, and the logistic spaces is a logistic parameter. All these parameters, or factors, are presented in Table 5 with the selected values and description.

Table 5. Control factors and selected levels for the Design of Experiments.

\begin{tabular}{cccccc}
\hline ID & Control Factors & Level 1 & Level 2 & Level 2 & Summary \\
\hline 1 & Minimum distance & $500 \mathrm{~mm}$ & $700 \mathrm{~mm}$ & $900 \mathrm{~mm}$ & $\begin{array}{c}\text { Minimum distances between } \\
\text { two generic resources } \\
\text { Speed adopted by the robot to } \\
\text { carry out the inspection } \\
\text { ins }\end{array}$ \\
3 & Robot speed & $0.25 \mathrm{~m} / \mathrm{s}$ & $0.5 \mathrm{~m} / \mathrm{s}$ & $0.75 \mathrm{~m} / \mathrm{s}$ & $\begin{array}{c}\text { Relative position of the infeed } \\
\text { and outfeed spaces }\end{array}$ \\
\hline
\end{tabular}

By the combination of these factors, a Design of Experiments (DoE) is made with a total of 27 combinations. Such configurations need to be evaluated through different performances with a set of functions. Consequently, an utility value is calculated for each configuration with the SMART method in order to provide a representative score. The proposed functions are: (i) the impact on space, (ii) the HRC relevance, (iii) the time cycle, and (iv) the initial investment cost. Three of that functions need to be minimized whereas the HRC relevance to be maximized. Such functions represent performances with competitive priorities, that means the improvement of one implies the worsening of 
another. They are reported with the SMART function in Table 6 with their expressions and the descriptions.

Table 6. Evaluation functions [34,35].

\begin{tabular}{|c|c|c|c|}
\hline Name & Function & Objective & Summary \\
\hline Impact on space & $\frac{A_{r}}{A_{t}} 100$ & Minimize & $\begin{array}{l}\text { Percentage of the total plant available area } \\
\text { occupied by the collaborative workplace }\end{array}$ \\
\hline HRC relevance & $\frac{T_{c}}{T_{t}} 100$ & Maximize & $\begin{array}{l}\text { Percentage of the total needed execution } \\
\text { time characterized by the simultaneous } \\
\text { working of human and robot }\end{array}$ \\
\hline Time & $\sum_{i=1}^{N} t_{i}$ & Minimize & Total needed execution time \\
\hline Cost & $\sum_{i=1}^{R} c_{i} n_{i}$ & Minimize & $\begin{array}{l}\text { Total cost as the sum of all the active and } \\
\text { passive resources }\end{array}$ \\
\hline SMART & $\sum_{i=1}^{F} a_{i} f_{i}$ & Maximize & $\begin{array}{l}\text { Weighted combination of the } \\
\text { previous functions }\end{array}$ \\
\hline
\end{tabular}

The impact on space compares the envelope of the occupied area $\left(A_{r}\right)$ with the reference value $\left(A_{t}\right)$ representing the total available workplace area. In this study, the reference value is $49 \mathrm{~m}^{2}$. The time is the sum of the single time of all the sequential tasks $\left(t_{i}\right)$. The HRC relevance is provided by the percentage of the collaborative time $\left(T_{c}\right)$ on the total time $\left(T_{t}\right)$. Finally, the cost is the sum of the costs of each resource $\left(c_{i}\right)$ on the workplace multiplied by the number of them $\left(n_{i}\right)$.

All the 27 configurations generated by means of the proposed approach are firstly evaluated by the four functions. Consequently, the SMART is adopted to obtain a synthetic score. It is provided by the weighted sum of the other functions once they are normalized on a scale between 0 and 100, where the worse value corresponds to 0 and the best value to 100. The necessary weights $\left(a_{i}\right)$ assigned to the normalized functions $\left(f_{i}\right)$, in accordance to the relative importance of each function on the collaborative workplace performances, are the following:

- Impact on space: $38 \%$;

- HRC relevance: $13 \%$;

- Time: $13 \%$;

- Cost: $38 \%$.

Indeed, the industrial experience suggests to pose a higher attention on the minimization of spaces and costs.

\section{Results and Discussion}

By applying the proposed approach and combining the three levels of the three control factors presented in the previous section, 27 alternatives of the same workplace are generated. Figure 10 presents three examples of the generated layouts which differ for the position of the logistic spaces. The application of the proposed approach allows obtaining 27 layout alternatives all of them in compliance with the reference standards. The values of the minimum distance among the resources are greater than the one established by the standards. Furthermore, the approach considers the relationship between minimum distances and some ergonomic aspects: the minimum distance is greater than the safety threshold value, whereas it is less than the maximum load carrying distance defined as a function of the carried cumulative mass (see Section 4.3). The productive aspect is also taken into account since the minimization of the occupied floor allows taking the resources closer, minimizing travel time of operator and reducing the cycle time. 

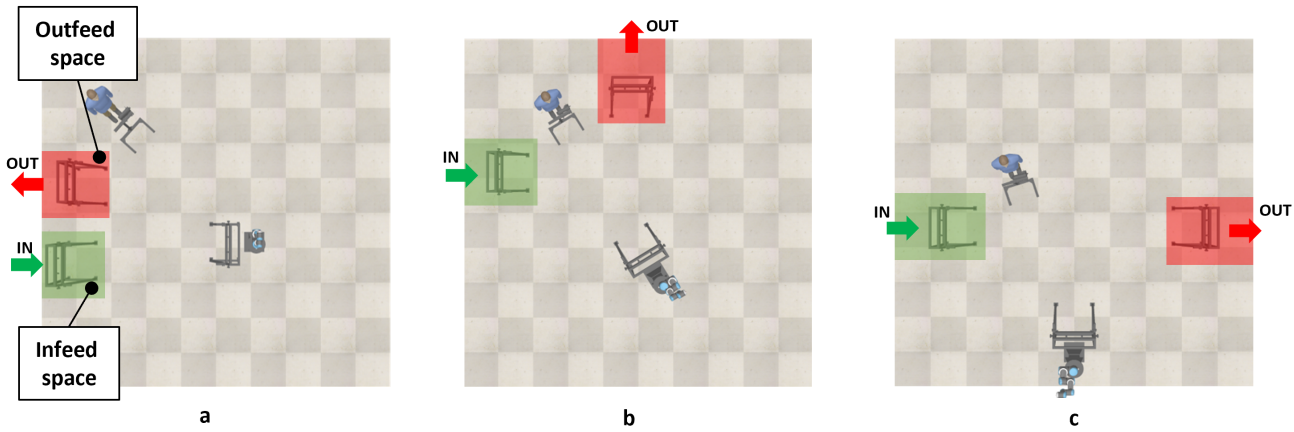

Figure 10. Three different workplace configurations obtained by changing the position of the logistic spaces: (a) infeed and outfeed spaces are placed on the same side; (b) infeed and outfeed spaces are placed on consecutive sides; (c) infeed and outfeed spaces are placed on opposite sides.

All the 27 scenarios are evaluated independently through the four KPIs presented in Section 5.2. The impact on space, the HRC relevance, the time and the cost are calculated for each configuration and a synthetic value given by the combination of them is pulled out by means of the SMART technique. In Table 7, the results of this assessment are presented. The combination of the three parameters provides the configuration number. The corresponding value of each function is presented, as well as the SMART utility value, calculated by the weighted combination of the other functions as depicted in Table 6.

Table 7. Design of Experiment and resulting function values calculated as explained in Table 6.

\begin{tabular}{|c|c|c|c|c|c|c|c|c|}
\hline Conf. & $\begin{array}{c}\text { Minimum } \\
\text { Distance }\end{array}$ & $\begin{array}{l}\text { Robot } \\
\text { Speed }\end{array}$ & Logistic Spaces & $\begin{array}{c}\text { Impact on } \\
\text { Space }\end{array}$ & $\begin{array}{c}\text { HRC } \\
\text { Relevance }\end{array}$ & Time & Cost & SMART \\
\hline 1 & 500 & 0.25 & Same side & 16.72 & 91.35 & 175.16 & 3000 & 87.76 \\
\hline 2 & 500 & 0.25 & Consecutive side & 17.30 & 90.87 & 176.08 & 3000 & 84.59 \\
\hline 3 & 500 & 0.25 & Opposite side & 23.74 & 90.20 & 177.39 & 3000 & 54.30 \\
\hline 4 & 500 & 0.5 & Same side & 16.90 & 83.97 & 95.28 & 3000 & 90.44 \\
\hline 5 & 500 & 0.5 & Consecutive side & 17.43 & 83.16 & 96.19 & 3000 & 87.26 \\
\hline 6 & 500 & 0.5 & Opposite side & 23.98 & 82.04 & 97.51 & 3000 & 56.08 \\
\hline 7 & 500 & 0.75 & Same side & 17.10 & 77.58 & 68.75 & 3000 & 87.63 \\
\hline 8 & 500 & 0.75 & Consecutive side & 17.64 & 76.56 & 69.66 & 3000 & 84.22 \\
\hline 9 & 500 & 0.75 & Opposite side & 24.26 & 75.14 & 70.98 & 3000 & 52.54 \\
\hline 10 & 700 & 0.25 & Same side & 18.12 & 91.27 & 175.31 & 3000 & 81.21 \\
\hline 11 & 700 & 0.25 & Consecutive side & 18.62 & 90.72 & 176.36 & 3000 & 78.39 \\
\hline 12 & 700 & 0.25 & Opposite side & 24.10 & 90.20 & 177.39 & 3000 & 52.65 \\
\hline 13 & 700 & 0.5 & Same side & 18.34 & 83.83 & 95.43 & 3000 & 83.68 \\
\hline 14 & 700 & 0.5 & Consecutive side & 18.78 & 82.92 & 96.48 & 3000 & 80.83 \\
\hline 15 & 700 & 0.5 & Opposite side & 24.33 & 82.04 & 97.51 & 3000 & 54.48 \\
\hline 16 & 700 & 0.75 & Same side & 18.54 & 77.41 & 68.90 & 3000 & 80.83 \\
\hline 17 & 700 & 0.75 & Consecutive side & 19.02 & 76.25 & 69.95 & 3000 & 77.60 \\
\hline 18 & 700 & 0.75 & Opposite side & 24.59 & 75.14 & 70.98 & 3000 & 50.98 \\
\hline 19 & 900 & 0.25 & Same side & 19.45 & 91.19 & 175.47 & 3000 & 75.04 \\
\hline 20 & 900 & 0.25 & Consecutive side & 20.08 & 90.58 & 176.63 & 3000 & 71.50 \\
\hline 21 & 900 & 0.25 & Opposite side & 24.38 & 90.20 & 177.39 & 3000 & 51.33 \\
\hline 22 & 900 & 0.5 & Same side & 19.70 & 83.70 & 95.58 & 3000 & 77.28 \\
\hline 23 & 900 & 0.5 & Consecutive side & 20.29 & 82.69 & 96.75 & 3000 & 73.65 \\
\hline 24 & 900 & 0.5 & Opposite side & 24.61 & 82.04 & 97.51 & 3000 & 53.20 \\
\hline 25 & 900 & 0.75 & Same side & 19.92 & 77.23 & 69.05 & 3000 & 74.32 \\
\hline 26 & 900 & 0.75 & Consecutive side & 20.52 & 75.95 & 70.22 & 3000 & 70.44 \\
\hline 27 & 900 & 0.75 & Opposite side & 24.86 & 75.14 & 70.98 & 3000 & 49.74 \\
\hline
\end{tabular}


According to the SMART, it emerged that the best configuration is the no. 4, characterized by:

- Minimum distance: $500 \mathrm{~mm}$;

- Robot speed: $0.5 \mathrm{~m} / \mathrm{s}$;

- Logistic spaces: the same side.

On another hand, other configurations are considered the best according to the other KPIs. Configuration no. 1 is the one that has the best score for impact on space and the HRC relevance, whereas configuration no. 7 is the one that minimizes the time. Furthermore, the cost is not considered because it provides the same value for all the configurations since the same resources are adopted in all the configurations.

Therefore, looking at the best configurations to select, a preliminary assessment leads to the following consideration:

1. The minimum distance to consider among the resources should be as less as possible. Indeed a minimum distance of $500 \mathrm{~mm}$ is the best according all the evaluation functions and the utility value.

2. The logistic spaces are located at the same side for all the winning configurations.

3. The robot speed presents a different result. Indeed, the minimum value is considered the best according to the impact on space and the HRC relevance, the middle value is the best solution according to SMART and the maximum value is the best for the time.

Some consideration can be done to confirm the above results. The closer the resources are, less the shop floor space utilisation is, as emerged in [35], where two different configurations present different values of impact on space. The configuration with the resources placed closer each other has the less space utilization. Furthermore, the closeness of the resources, as well as the higher robot speed, lead to a less time cycle to perform the task schedule $[35,65]$. On another hand, the position of the logistic spaces is an input parameter considered by [65], but not investigated. Due to the provided considerations, apparently, the best designing should follow the minimization of the distance among the resources and the positioning of the logistic spaces at the same side. About the robot speed, it should be set according to the interest of the designer and the company. Nevertheless, an ANOVA analysis conducted on the results leads us to discover the magnitude of the impact that the three parameters have on the functions, in order to find out which of them is the most influential. The analysis is carried out on the utility value and three on the four KPIs. The initial investment function is not considered because its value does not change for all the configurations. The main effect of the parameters as well as the combined effects are considered. The resume of the analysis is presented in Table 8 . The final considerations are the following:

- The relative position of the logistic spaces is very significant on the impact on space and the SMART utility value ( $88.88 \%$ and $90.68 \%)$;

- The robot speed is very significant on the collaborative time and total time of execution (99.96\% and $98.60 \%)$;

- The minimum distance has a very low impact on all the performances (less than $9 \%$ on all the functions);

- No interaction effect is significant for all the performance (less that $1 \%$ ). 
Table 8. Results of the ANOVA analysis.

\begin{tabular}{cccc}
\hline \multicolumn{2}{c}{ ANOVA Analysis } \\
\hline \multicolumn{3}{c}{ Impact on space } \\
\hline $\begin{array}{c}\text { SMAnT } \\
\text { Robot speed }\end{array}$ & $8.14 \%$ & Minimum distance & $8.93 \%$ \\
Logistic spaces & $2.98 \%$ & Robot speed & $0.40 \%$ \\
\hline HRC relevance & $88.88 \%$ & Logistic spaces & $90.68 \%$ \\
\hline Minimum distance & $0.00 \%$ & Tinimum distance & $0.03 \%$ \\
Robot speed & $99.96 \%$ & Robot speed & $98.60 \%$ \\
Logistic spaces & $0.04 \%$ & Logistic spaces & $1.37 \%$ \\
\hline
\end{tabular}

Therefore, from this analysis it emerges that the minimum distance is not a significant factor for all the evaluation criteria. Indeed it has a very low impact on all the evaluation functions and it could be not considered as input for the generation of the scenarios. Its value can depend only on the economic and feasibility needs.

On another hand, the robot speed is one of the factors that impacts mostly on the total time and the collaborative time, as expected. Indeed, if the robot moves at a lower speed, there are two different aspects that come out: (i) it is allowed to human to stay close to the robot area and (ii) the shared time could increase or decrease its percentage on the total time depending on the task schedule. In contrast, if the robot move at the higher speed, it is forbidden to stay close to it, therefore the collaboration is penalized, even though the total cycle time decreases. Furthermore, if the robot task is carried out at the highest speed during the inspection, the control by the human gets worse.

Finally, the relative position of the logistic space is the most influential factor for SMART and impact on space. That is reasonable because the different layouts need different distribution of the resources on the space. Moreover, the impact on the space is the function with the highest weight in the SMART together with the cost. Therefore, the factor with the highest impact on such performances, has a comparable impact even on the SMART utility value.

Figure 11 shows the trend of the functions according to their main influential factors. The diagrams present all the functions reported on a scale from 0 to 100 where 0 corresponds to the worse condition and 100 the best condition. The trends of the SMART utility value and the impact on the space are reported according to the relative position of the logistic spaces. They have pretty similar trends as explained before (Figure 11a). In particular, it is possible to see that both the performances present very low changes when the logistic spaces are located at the same side or consecutive sides, but they get worse when the logistic spaces are located at opposite sides. This results suggests to adopt indifferently mainly logistic spaces at the same side or consecutive sides. On another hand, to locate the logistic spaces at opposite sides could lead to a worsening of the performance. The matter is different for the robot speed. The trend of total time and collaborative time are reported according to the robot speed. It is interesting to see that the collaborative time has a linear decreasing trend with the robot speed whereas the performance of the total time has a increasing trend (Figure 11b).

The analysis of the results leads to the following considerations. The minimum distance among the resource is not a important control factor on the KPIs, therefore it can be set following the criteria of minimum cost or another criterion. The relative position of the logistic spaces has a high impact on the use of space and the SMART utility value. In particular, when the logistic spaces are at opposite sides, there is a general worsening of these performances. Still, the robot speed presents a conflicting result. It is impossible to maximize the performance of the total time and collaborative time at the same time, even though the middle robot speed is a good compromise to achieve the best possible condition for both the KPIs. 


\section{Main effect plots}

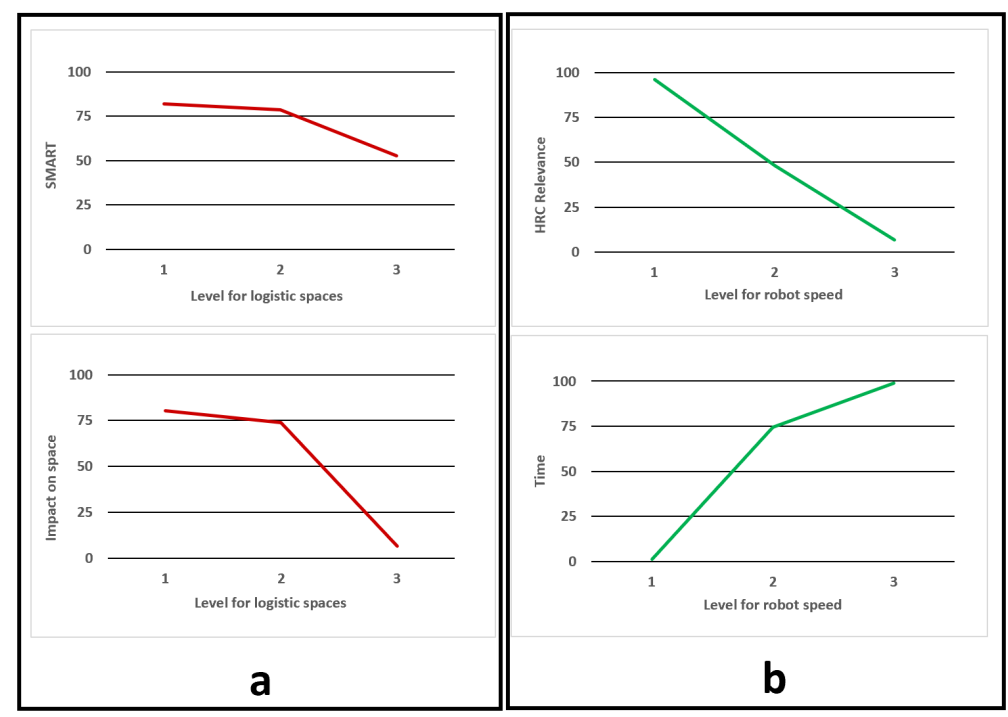

Figure 11. Main effect plots: (a) trend of the impact on space and SMART utility value according to the three levels for logistic spaces; (b) trend of the HRC Relevance and time according to the three levels for robot speed.

\section{Conclusions}

This paper presents a streamlined approach aimed at designing a collaborative workplace layout. Firstly, the context and the challenges of collaborative robotics are presented in order to define the boundaries of the problem. Consequently, all of the knowledge about collaborative robotics is systematically collected and managed, according to a KBA. A modeling paradigm is the outcome of this process; it allows for the definition of an approach for layout designing that leverages the positioning of the HTC and RTC in the available space, according to a defined optimization criterion. Finally, a what-if analysis is carried out by means of DoE, in order to generate a set of scenarios and evaluate them through four functions and one utility value.

The main contribution of the paper is the presentation of a modeling paradigm used to: (i) describe the relevant aspect common to several workplaces; (ii) simplify the implementation of design methods; (iii) identify changes in the layout of the workplaces. Hence, the designing approach, the aim of which is the spatial optimization and the standards compliance of the collaborative workplace layout, is proposed. This is applied to a collaborative workplace for quality ultrasonic inspection to prove its usefulness and feasibility. The case study allows showing the systematic usage of the designing approach, and carrying on a what-if analysis by generating multiple layout configurations. Three inputs are set as control factors: (i) the minimum distance among the resources, (ii) the robot speed, and (iii) the relative position of the logistic spaces. They are set on three levels. A Design of Experiments (DoE) made of 27 combinations is carried out and four Key Performance Indicators (KPIs) are selected to assess the layout alternatives. The KPIs simulated are: the impact on space, the execution time, the relevance of the collaboration (HRC relevance), and the initial investment cost. To obtain a utility value representative of each configuration, the SMART technique is adopted. Finally, an ANOVA analysis is carried out in order to find out the real impact of the control factors on each KPI. The results show that only one configuration is eligible as the best configuration according to the investigation, and only two out of three control factors are very significant for the designing of the HRC workplace layout. Concluding, the approach facilitates the designing process for multiple layout alternatives, always generated in the respect of the reference standards. Thus, by means of a what-if analysis, enabled by the application of the proposed approach, the designer can analyze different aspects of any collaborative 
workplace, bringing out the most influential designing constraints and parameters for both brown-field and green-field contexts.

Author Contributions: All authors contributed equally to this work. All authors have read and agreed to the published version of the manuscript.

Funding: This study was developed with the economic support of MUR (Ministry of Universities and Research) under the remit of project ARS01_00861, "Integrated collaborative systems for smart factory-ICOSAF".

Institutional Review Board Statement: Not applicable.

Informed Consent Statement: Not applicable.

Data Availability Statement: Data available on request.

Conflicts of Interest: The authors declare no conflict of interest. The funders had no role in the design of the study; in the collection, analyses, or interpretation of data; in the writing of the manuscript, or in the decision to publish the results.

\section{References}

1. Nahavandi, S. Industry 5.0-A human-centric solution. Sustainability 2019, 11, 4371. [CrossRef]

2. Parente, M.; Figueira, G.; Amorim, P.; Marques, A. Production Scheduling in the Context of Industry 4.0: Review and Trends. Int. J. Prod. Res. 2020, 58, 5401-5431. [CrossRef]

3. Djuric, A.M.; Urbanic, R.; Rickli, J. A Framework for Collaborative Robot (CoBot) Integration in Advanced Manufacturing Systems. SAE Int. J. Mater. Manuf. 2016, 9, 457-464. [CrossRef]

4. Tan, Q.; Tong, Y.; Wu, S.; Li, D. Anthropocentric Approach for Smart Assembly: Integration and Collaboration. J. Robot. 2019, 2019, 1-8. [CrossRef]

5. Di Marino, C.; Rega, A.; Vitolo, F.; Patalano, S.; Lanzotti, A. A New Approach to the Anthropocentric Design of Human-Robot Collaborative Environments. Acta IMEKO 2020, 9, 80-87. [CrossRef]

6. $\quad$ Krüger, J.; Wang, L.; Verl, A.; Bauernhansl, T.; Carpanzano, E.; Makris, S.; Fleischer, J.; Reinhart, G.; Franke, J.; Pellegrinelli, S. Innovative Control of Assembly Systems and Lines. CIRP Ann. 2017, 66, 707-730. [CrossRef]

7. International Federation of Robotics. World Robotics Industrial Robots; Technical Report; International Federation of Robotics: Frankfurt, Germany, 2019.

8. Gualtieri, L.; Rauch, E.; Rojas, R.; Vidoni, R.; Matt, D.T. Application of Axiomatic Design for the Design of a Safe Collaborative Human-Robot Assembly Workplace. MATEC Web Conf. 2018, 223, 01003. [CrossRef]

9. Vicentini, F. Collaborative Robotics: A Survey. J. Mech. Des. 2020, 143, 040802. [CrossRef]

10. Kusiak, A.; Heragu, S.S. The Facility Layout Problem. Eur. J. Oper. Res. 1987, 29, 229-251. [CrossRef]

11. Drira, A.; Pierreval, H.; Hajri-Gabouj, S. Facility Layout Problems: A Survey. Annu. Rev. Control 2007, 31, 255-267. [CrossRef]

12. Shiller, Z. Optimal Robot Motion Planning and Work-Cell Layout Design. Robotica 1997, 15, 31-40. [CrossRef]

13. Scimmi, L.S.; Melchiorre, M.; Troise, M.; Mauro, S.; Pastorelli, S. A Practical and Effective Layout for a Safe Human-Robot Collaborative Assembly Task. Appl. Sci. 2021, 11, 1763. [CrossRef]

14. Murali, P.; Darvish, K.; Mastrogiovanni, F. Deployment and Evaluation of a Flexible Human-Robot Collaboration Model Based on AND/OR Graphs in a Manufacturing Environment. Intell. Serv. Robot. 2020, 13, 439-457. [CrossRef]

15. Mateus, J.; Claeys, D.; Limère, V.; Cottyn, J.; Aghezzaf, E.H. Base Part Centered Assembly Task Precedence Generation. Int. J. Adv. Manuf. Technol. 2020, 107, 607-616. [CrossRef]

16. Bänziger, T.; Kunz, A.; Wegener, K. Optimizing Human-Robot Task Allocation Using a Simulation Tool Based on Standardized Work Descriptions. J. Intell. Manuf. 2020, 31, 1635-1648. [CrossRef]

17. Kim, W.; Peternel, L.; Lorenzini, M.; Babič, J.; Ajoudani, A. A Human-Robot Collaboration Framework for Improving Ergonomics During Dexterous Operation of Power Tools. Robot.-Comput.-Integr. Manuf. 2021, 68, 102084. [CrossRef]

18. Abobakr, A.; Nahavandi, D.; Hossny, M.; Iskander, J.; Attia, M.; Nahavandi, S.; Smets, M. RGB-D Ergonomic Assessment System of Adopted Working Postures. Appl. Ergon. 2019, 80, 75-88. [CrossRef]

19. Paletta, L.; Pszeida, M.; Nauschnegg, B.; Haspl, T.; Marton, R. Stress Measurement in Multi-Tasking Decision Processes Using Executive Functions Analysis. Adv. Intell. Syst. Comput. 2020, 953, 344-356. [CrossRef]

20. Colim, A.; Faria, C.; Braga, A.C.; Sousa, N.; Rocha, L.; Carneiro, P.; Costa, N.; Arezes, P. Towards an Ergonomic Assessment Framework for Industrial Assembly Workstations-A Case Study. Appl. Sci. 2020, 10, 3048. [CrossRef]

21. Rojas, R.; Wehrle, E.; Vidoni, R. A Multicriteria Motion Planning Approach for Combining Smoothness and Speed in Collaborative Assembly Systems. Appl. Sci. 2020, 10, 5086. [CrossRef]

22. Matsas, E.; Vosniakos, G.C. Design of a Virtual Reality Training System for Human-Robot Collaboration in Manufacturing Tasks. Int. J. Interact. Des. Manuf. 2017, 11, 139-153. [CrossRef] 
23. ISO 10218-1:2011. Robots and Robotic Devices-Safety Requirements for Industrial Robots-Part 1: Robots; International Organization for Standardization: Geneva, Switzerland, 2011.

24. ISO 10218-2:2011. Robots and Robotic Devices-Safety Requirements for Industrial Robots-Part 2: Robot Systems and Integration; International Organization for Standardization: Geneva, Switzerland, 2011.

25. ISO \TS 15066:2016. Robots and Robotic Devices: Collaborative Robots; International Organization for Standardization: Geneva, Switzerland, 2011.

26. Bdiwi, M.; Pfeifer, M.; Sterzing, A. A New Strategy for Ensuring Human Safety during Various Levels of Interaction with Industrial Robots. CIRP Ann. 2017, 66, 453-456. [CrossRef]

27. Aaltonen, I.; Salmi, T.; Marstio, I. Refining Levels of Collaboration to Support the Design and Evaluation of Human-Robot Interaction in the Manufacturing Industry. Procedia CIRP 2018, 72, 93-98. [CrossRef]

28. El Zaatari, S.; Marei, M.; Li, W.; Usman, Z. Cobot Programming for Collaborative Industrial Tasks: An Overview. Robot. Auton. Syst. 2019, 116, 162-180. [CrossRef]

29. Matheson, E.; Minto, R.; Zampieri, E.G.G.; Faccio, M.; Rosati, G. Human-Robot Collaboration in Manufacturing Applications: A Review. Robotics 2019, 8, 100. [CrossRef]

30. Malik, A.A.; Bilberg, A. Developing a Reference Model for Human-Robot Interaction. Int. J. Interact. Des. Manuf. 2019, 13, 1541-1547. [CrossRef]

31. Malik, A.; Brem, A. Digital Twins for Collaborative Robots: A Case Study in Human-Robot Interaction. Robot. Comput. Integr. Manuf. 2021, 68, 102092. [CrossRef]

32. Kousi, N.; Gkournelos, C.; Aivaliotis, S.; Lotsaris, K.; Bavelos, A.C.; Baris, P.; Michalos, G.; Makris, S. Digital Twin for Designing and Reconfiguring Human-Robot Collaborative Assembly Lines. Appl. Sci. 2021, 11, 4620. [CrossRef]

33. Boschetti, G.; Bottin, M.; Faccio, M.; Minto, R. Multi-Robot Multi-Operator Collaborative Assembly Systems: A Performance Evaluation Model. J. Intell. Manuf. 2021, 32, 1455-1470. [CrossRef]

34. Faccio, M.; Minto, R.; Rosati, G.; Bottin, M. The Influence of the Product Characteristics on Human-Robot Collaboration: A Model for the Performance of Collaborative Robotic Assembly. Int. J. Adv. Manuf. Technol. 2020, 106, 2317-2331. [CrossRef]

35. Tsarouchi, P.; Michalos, G.; Makris, S.; Athanasatos, T.; Dimoulas, K.; Chryssolouris, G. On a Human-Robot Workplace Design and Task Allocation System. Int. J. Comput. Integr. Manuf. 2017, 30, 1272-1279. [CrossRef]

36. Ore, F.; Sánchez, J.L.J.; Wiktorsson, M.; Hanson, L. Design Method of Human-Industrial Robot Collaborative Workstation with Industrial Application. Int. J. Comput. Integr. Manuf. 2020, 33, 911-924. [CrossRef]

37. Lietaert, P.; Billen, N.; Burggraeve, S. Model-Based Multi-Attribute Collaborative Production Cell Layout Optimization. In Proceedings of the 2019 20th International Conference on Research and Education in Mechatronics (REM), Wels, Austria, 23-24 May 2019; pp. 1-7. [CrossRef]

38. Mateus, J.C.; Claeys, D.; Limère, V.; Cottyn, J.; Aghezzaf, E.H. A Structured Methodology for the Design of a Human-Robot Collaborative Assembly Workplace. Int. J. Adv. Manuf. Technol. 2019, 102, 2663-2681. [CrossRef]

39. Saenz, J.; Behrens, R.; Schulenburg, E.; Petersen, H.; Gibaru, O.; Neto, P.; Elkmann, N. Methods for Considering Safety in Design of Robotics Applications Featuring Human-Robot Collaboration. Int. J. Adv. Manuf. Technol. 2020, 107, 2313-2331. [CrossRef]

40. Gervasi, R.; Mastrogiacomo, L.; Franceschini, F. A Conceptual Framework to Evaluate Human-Robot Collaboration. Int. J. Adv. Manuf. Technol. 2020, 108, 841-865. [CrossRef]

41. Ralyté, J.; Jeusfeld, M.; Backlund, P.; Kühn, H.; Arni-Bloch, N. A Knowledge-Based Approach to Manage Information Systems Interoperability. Inf. Syst. 2008, 33, 754-784. [CrossRef]

42. Favi, C.; Garziera, R.; Campi, F. A Rule-Based System to Promote Design for Manufacturing and Assembly in the Development of Welded Structure: Method and Tool Proposition. Appl. Sci. 2021, 11, 2326. [CrossRef]

43. Li, Z.; Liang, P.; Avgeriou, P. Application of Knowledge-Based Approaches in Software Architecture: A Systematic Mapping Study. Inf. Softw. Technol. 2013, 55, 777-794. [CrossRef]

44. Aulinas, M.; Nieves, J.; Cortés, U.; Poch, M. Supporting Decision Making in Urban Wastewater Systems Using a Knowledge-Based Approach. Environ. Model. Softw. 2011, 26, 562-572. [CrossRef]

45. Ansari, F.; Hold, P.; Khobreh, M. A Knowledge-Based Approach for Representing Jobholder Profile toward Optimal Human-Machine Collaboration in Cyber Physical Production Systems. CIRP J. Manuf. Sci. Technol. 2020, 28, 87-106. [CrossRef]

46. Michalos, G.; Makris, S.; Tsarouchi, P.; Guasch, T.; Kontovrakis, D.; Chryssolouris, G. Design Considerations for Safe HumanRobot Collaborative Workplaces. Procedia CIRP 2015, 37, 248-253. [CrossRef]

47. Villani, V.; Pini, F.; Leali, F.; Secchi, C. Survey on Human-Robot Collaboration in Industrial Settings: Safety, Intuitive Interfaces and Applications. Mechatronics 2018, 55, 248-266. [CrossRef]

48. Matthias, B.; Reisinger, T. Example Application of ISO/TS 15066 to a Collaborative Assembly Scenario. In Proceedings of the ISR 2016: 47st International Symposium on Robotics, Rome, Italy, 21-22 June 2016; pp. 1-5.

49. Bauer, W.; Bender, M.; Braun, M.; Rally, P.; Scholtz, O. Lightweight Robots in Manual Assembly-Best to Start Simply. Examining Companies' Initial Experiences with Lightweight Robots; Frauenhofer-Institut für Arbeitswirtschaft und Organisation IAO: Stuttgart, Germany, 2016. 
50. TechNavio. Global Collaborative Robots Market 2020-2024 (Research and Markets). 2020. Available online: https: //www.businesswire.com/news/home/20200804005683/en/Analysis-on-Impact-of-COVID-19--Global-CollaborativeRobots-Market-2020-2024-Evolving-Opportunities-with-ABB-Ltd.-and-FANUC-Corp.-Technavio (accessed on 10 December 2021).

51. Deo, N. Graph Theory with Applications to Engineering and Computer Science; Dover Publications: Mineola, NY, USA, 2017.

52. Majeed, A.; Rauf, I. Graph Theory: A Comprehensive Survey about Graph Theory Applications in Computer Science and Social Networks. Inventions 2020, 5, 10. [CrossRef]

53. Schaeffer, S.E. Graph Clustering. Comput. Sci. Rev. 2007, 1, 27-64. [CrossRef]

54. Marvel, J.A.; Falco, J.; Marstio, I. Characterizing Task-Based Human-Robot Collaboration Safety in Manufacturing. IEEE Trans. Syst. Man, Cybern. Syst. 2015, 45, 260-275. [CrossRef]

55. Pheasant, S.; Haslegrave, C.M. Bodyspace: Anthropometry, Ergonomic and the Design of Work, 3rd ed.; CRC Press: Boca Raton, FL, USA, 2018.

56. Bazaraa, M.; Sherali, H.; Shetty, C. Nonlinear Programming: Theory and Algorithms; Wiley: Hoboken, NJ, USA, 2005 ; p. 853. [CrossRef]

57. ISO 13854:2017. Safety of Machinery-Minimum Gaps to Avoid Crushing of Parts of the Human Body; International Organization for Standardization: Geneva, Switzerland, 1993.

58. ISO 12100:2010. Safety of Machinery-General Principles for Design-Risk Assessment and Risk Reduction; International Organization for Standardization: Geneva, Switzerland, 2010.

59. ISO 13850:2015. Safety of Machinery-Emergency Stop Function-Principles for Design; International Organization for Standardization: Geneva, Switzerland, 2015.

60. ISO 11228-1:2003. Ergonomics-Manual Handling-Part 1: Lifting and Carrying; International Organization for Standardization: Geneva, Switzerland, 2003.

61. ISO 13849-1:2015. Safety of Machinery-Safety-Related Parts of Control Systems-Part 1: General Principles for Design; International Organization for Standardization: Geneva, Switzerland, 2015.

62. Siregar, D.; Arisandi, D.; Usman, A.; Irwan, D.; Rahim, R. Research of Simple Multi-Attribute Rating Technique for Decision Support. J. Physics Conf. Ser. 2017, 930, 012015. [CrossRef]

63. Risawandi.; Rahim, R. Study of the Simple Multi-Attribute Rating Technique For Decision Support. Int. J. Sci. Res. Sci. Technol. 2016, 2, 491-494.

64. Barron, F.H.; Barrett, B.E. The Efficacy of SMARTER—Simple Multi-Attribute Rating Technique Extended to Ranking Acta Psychol. 1996, 93, 23-36. [CrossRef]

65. Ore, F.; Vemula, B.; Hanson, L.; Wiktorsson, M.; Fagerström, B. Simulation Methodology for Performance and Safety Evaluation of Human-Industrial Robot Collaboration Workstation Design. Int. J. Intell. Robot. Appl. 2019, 3, 269-282. [CrossRef] 